\title{
A new model of the global biogeochemical cycle of carbonyl sulfide - Part 2: Use of carbonyl sulfide to constrain gross primary productivity in current vegetation models
}

\author{
T. Launois ${ }^{1, \mathrm{a}}$, P. Peylin ${ }^{1}$, S. Belviso ${ }^{1}$, and B. Poulter ${ }^{1}$ \\ ${ }^{1}$ Laboratoire des Sciences du Climat et de l'Environnement (LSCE), IPSL, CEA, CNRS, UVSQ, CE Saclay, \\ Bât 701 L'Orme des Merisiers, 91191, Gif-sur-Yvette, France \\ anow at: INRA, UMR 1391 ISPA, 33140 Villenave d'Ornon, France
}

Correspondence to: T. Launois (thomas.launois@1sce.ipsl.fr)

Received: 3 September 2014 - Published in Atmos. Chem. Phys. Discuss.: 5 November 2014

Revised: 20 July 2015 - Accepted: 3 August 2015 - Published: 20 August 2015

\begin{abstract}
Clear analogies between carbonyl sulfide (OCS) and carbon dioxide $\left(\mathrm{CO}_{2}\right)$ diffusion pathways through leaves have been revealed by experimental studies, with plant uptake playing an important role for the atmospheric budget of both species. Here we use atmospheric OCS to evaluate the gross primary production (GPP) of three dynamic global vegetation models (Lund-Potsdam-Jena, LPJ; National Center for Atmospheric Research - Community Land Model 4, NCAR-CLM4; and Organising Carbon and Hydrology In Dynamic Ecosystems, ORCHIDEE). Vegetation uptake of OCS is modeled as a linear function of GPP and leaf relative uptake (LRU), the ratio of OCS to $\mathrm{CO}_{2}$ deposition velocities of plants. New parameterizations for the nonphotosynthetic sinks (oxic soils, atmospheric oxidation) and biogenic sources (oceans and anoxic soils) of OCS are also provided. Despite new large oceanic emissions, global OCS budgets created with each vegetation model show exceeding sinks by several hundred $\mathrm{Gg} \mathrm{S} \mathrm{yr}^{-1}$. An inversion of the surface fluxes (optimization of a global scalar which accounts for flux uncertainties) led to balanced OCS global budgets, as atmospheric measurements suggest, mainly by drastic reduction (up to $-50 \%$ ) in soil and vegetation uptakes.

The amplitude of variations in atmospheric OCS mixing ratios is mainly dictated by the vegetation sink over the Northern Hemisphere. This allows for bias recognition in the GPP representations of the three selected models. The main bias patterns are (i) the terrestrial GPP of ORCHIDEE at high northern latitudes is currently overestimated, (ii) the seasonal variations of the GPP are out of phase in the NCAR-
\end{abstract}

CLM4 model, showing a maximum carbon uptake too early in spring in the northernmost ecosystems, (iii) the overall amplitude of the seasonal variations of GPP in NCAR-CLM4 is too small, and (iv) for the LPJ model, the GPP is slightly out of phase for the northernmost ecosystems and the respiration fluxes might be too large in summer in the Northern Hemisphere. These results rely on the robustness of the OCS modeling framework and, in particular, the choice of the LRU values (assumed constant in time) and the parameterization of soil OCS uptake with small seasonal variations. Refined optimization with regional-scale and seasonally varying coefficients might help to test some of these hypothesis.

\section{Introduction}

The continental biosphere is an integral component of the climate system, and of the carbon and water cycles: it has absorbed about a quarter of the $\mathrm{CO}_{2}$ released into the atmosphere by anthropogenic activities (Working Group I Contribution to the IPCC Fifth Assessment Report (AR5), Climate Change 2013: The Physical Science Basis) and it modulates the water balance over land. The functioning of the terrestrial biosphere can be heavily affected by climate change in particular by the assumed increase in climate extreme events (Grace and Rayment, 2000; Piovesan and Adams, 2000; Ciais et al., 2005; Schaphoff et al., 2006; Poulter et al., 2014). These events have the potential to reduce photosynthesis or increase ecosystem respiration (e.g., the impact of the Eu- 
ropean heat wave in 2003 addressed by Ciais et al., 2005). Quantifying carbon storage by ecosystem and predicting its sensitivity to future climate change relies heavily on our ability to determine the separate fluxes of photosynthesis and respiration at different scales. Terrestrial gross primary productivity (GPP) remains poorly constrained at global scales, with recent estimates differing by $30-40 \mathrm{Pg} \mathrm{C} \mathrm{yr}^{-1}$ (Beer et al., 2010; Ahlström et al., 2015).

The net ecosystem exchange (NEE) flux can be measured continuously with the eddy-correlation technique at site level. However, GPP is not directly measurable. Indirect approaches have been proposed to estimate the biospheric gross fluxes (GPP and respiration), for instance, by using differences between nighttime and daytime NEE measurements (Reichstein et al., 2005; Lasslop et al., 2010) or combining different tracers including stable isotopologues of $\mathrm{CO}_{2}\left({ }^{13} \mathrm{C}\right.$ and ${ }^{18} \mathrm{O}$ ) (Knohl et al., 2005; Scartazza et al., 2004; Wingate et al., 2010). However, the underlying hypotheses in these approaches impose limitations, and the poor knowledge of the isotopic signatures of different gross fluxes and their temporal variations when using ${ }^{13} \mathrm{C}$ and ${ }^{18} \mathrm{O}$ data are especially limiting. Moreover, when local measurements are used to calibrate or compare with large-scale estimates, the process of extrapolation creates further uncertainty.

Carbonyl sulfide (OCS) is now measured at several atmospheric monitoring stations, and its use as a tracer promises to bring new constraints on the gross fluxes of $\mathrm{CO}_{2}$. The concept is based on the absorption of OCS by vegetation being directly linked to that of $\mathrm{CO}_{2}$. Although there is compelling evidence that OCS uptake at the leaf scale is essentially a one-way process (Sandoval-Soto, 2005; Seibt et al., 2010), the link between OCS absorption and photosynthesis is more complex than expected because OCS absorption also takes place during night and because the leaf relative uptake ratios of OCS and $\mathrm{CO}_{2}$ during photosynthesis vary with light level (Maseyk et al., 2014). At larger scales (ecosystems, regions or continents), the link between OCS absorption and photosynthesis is also weaker than expected because soils take up atmospheric OCS too and can turn from a net sink to a net source, depending on whether or not they are saturated. If atmospheric OCS data are to be used to constrain fluxes in global modeling studies, there is no other option than to characterize the spatiotemporal variations in sources and sinks of this gas (Kettle et al., 2002; Suntharalingam et al., 2008; Berry et al., 2013).

Atmospheric records of OCS mixing ratios exhibit clear seasonal variations. Maximal and minimal values for OCS concentrations are observed in winter and late summer, respectively, and the seasonal variations of OCS are highly correlated with those of $\mathrm{CO}_{2}$ (Montzka and Tans, 2004).

Here, we use OCS to constrain the annual, seasonal and spatial variations of GPP of three dynamic global vegetation models (DGVMs): Lund-Potsdam-Jena (LPJ; Sitch et al., 2003), National Center for Atmospheric Research - Community Land Model 4 (NCAR-CLM4, hereafter referred to as CLM4CN; Thornton et al., 2007), and Organising Carbon and Hydrology In Dynamic Ecosystems (ORCHIDEE, hereafter referred to as ORC; Krinner et al., 2005). These DGVMs exhibit contrasting global photosynthetic carbon fluxes (120, 130 and $160 \mathrm{Pg} \mathrm{C} \mathrm{yr}^{-1}$, respectively). The differences in GPP involve not only the annual global total but also the phase and amplitude of the seasonal variations. All three tested DGVMs were chosen according to the results of the TRENDY experiment, which compared trends in global and regional $\mathrm{CO}_{2}$ fluxes over the last 2 decades (TRENDY experiment, Ahlström et al., 2015). For this, we modeled the vegetation OCS sink as proportional to GPP and the leaf relative uptake (LRU), where LRU values were taken from the inventory of Seibt et al. (2010), together with new parameterizations of the non-photosynthetic sinks of OCS (oxic soils and atmospheric oxidation) and of its biogenic emissions (from oceans and anoxic soils). To evaluate our current understanding and representational accuracy of the OCS biogeochemical cycle and quantify the relative impact of each surface flux, we transported those fluxes using the atmospheric Laboratoire de Météorologie Dynamique Zoom (LMDZ) transport model and compared simulated OCS atmospheric concentrations to observations from a database assembled by NOAA/ESRL. In the next step, we define uncertainties associated with each surface flux and optimized these fluxes with an inverse modeling approach to minimize the difference in OCS atmospheric concentrations between simulations and observations.

With the results of these simulations, we successively investigate the following questions:

1. How does our revised parameterization of surface fluxes (oceanic emissions, soil and leaf uptakes) compare with the temporal and spatial variations of atmospheric OCS?

2. What is the sensitivity of the phase and amplitude of the simulated seasonal cycles and the sensitivity of the latitudinal gradient of OCS concentrations to changes in surface fluxes?

3. Given the current uncertainties in the surface fluxes, how well would optimized fluxes compare with the observed time series of atmospheric OCS?

4. Can we use the OCS atmospheric observations to benchmark the GPP simulated by current DGVMs, given the uncertainties in OCS surface processes?

In the first section, we describe our new set of tropospheric global sources and sinks of OCS and discuss the spatial and temporal distribution of the fluxes. In the second section, we investigate the resulting OCS atmospheric concentration using a forward modeling approach. We then analyze the results of the inverse approach in terms of model-data fit and impact on the fluxes. We finally discuss the potential constraint from these results on the GPP of each DGVM. 


\section{Material and methods}

\subsection{Atmospheric $\mathrm{OCS}$ and $\mathrm{CO}_{2}$ observations}

Atmospheric OCS and $\mathrm{CO}_{2}$ concentrations used in this work are from the NOAA/ESRL (National Oceanic and Atmospheric Administration Earth System Research Laboratory Global Monitoring Division flask program) database, where OCS measurements from 10 stations have been gathered since 2000 (Montzka and Tans, 2004). These stations include nine background sites (SPO, South Pole; CGO, Cape Grim, Tasmania, Australia; SMO, American Samoa; MLO, Mauna Loa, Hawaii, United States; NWR, Niwot Ridge, Colorado, United States; BRW, Barrow, Alaska, United States; ALT, Alert, Nunavut, Canada; MHD, Mace Head, Ireland; KUM, Cape Kumukahi, Hawaii, United States) and a single continental site (LEF, Park Falls, Wisconsin, United States). The location of stations is shown in Fig. 1.

Samples were analyzed using gas chromatography and mass spectrometry. OCS data are available for the scientific community at ftp://ftp.cmdl.noaa.gov/hats/carbonylsulfide/. The typical measurement error for OCS is around $6 \mathrm{ppt}$, a value much lower than the transport model error. $\mathrm{CO}_{2}$ data used in this study were downloaded from ftp://ftp.cmdl.noaa. gov/ccg/co2/. For $\mathrm{CO}_{2}$, we assumed a standard $0.1 \mathrm{ppm}$ measurement error for the observations. More details of the OCS and $\mathrm{CO}_{2}$ measurement techniques are given by Montzka and Tans (2004).

\subsection{The different surface OCS fluxes and their representation in models}

\subsubsection{Sea-to-air emissions of OCS}

OCS is emitted from the oceans to the atmosphere either directly, because surface waters are generally supersaturated in OCS, or indirectly through oxidation of atmospheric dimethylsulfide (DMS) and carbon disulfide $\left(\mathrm{CS}_{2}\right)$ which are both produced in the surface layer of the ocean. Oceans are a major source of OCS (Kettle et al., 2002). Berry et al. (2013) found that the marine source accounted for $876 \mathrm{Gg} \mathrm{S} \mathrm{yr}^{-1}$, about $74 \%$ of total sources, but this estimate was not well constrained since the authors increased the direct marine emissions of Kettle et al. (2002) by $600 \mathrm{Gg} \mathrm{S} \mathrm{yr}^{-1}$ to provide a balanced global budget of OCS (Table 2).

Here, the direct emissions are based on parameterizations of ocean production and removal processes of OCS implemented in the NEMO-PISCES oceanic general circulation and biogeochemistry model (Launois et al., 2015). These parameterizations lead to a direct ocean emission of $813 \mathrm{Gg} \mathrm{S} \mathrm{yr}^{-1}$. We further accounted for indirect emissions of OCS both from DMS and from $\mathrm{CS}_{2}$. Details of the parameterizations for the direct and indirect ocean emissions are provided in Appendix A1. Note that for the optimizations,

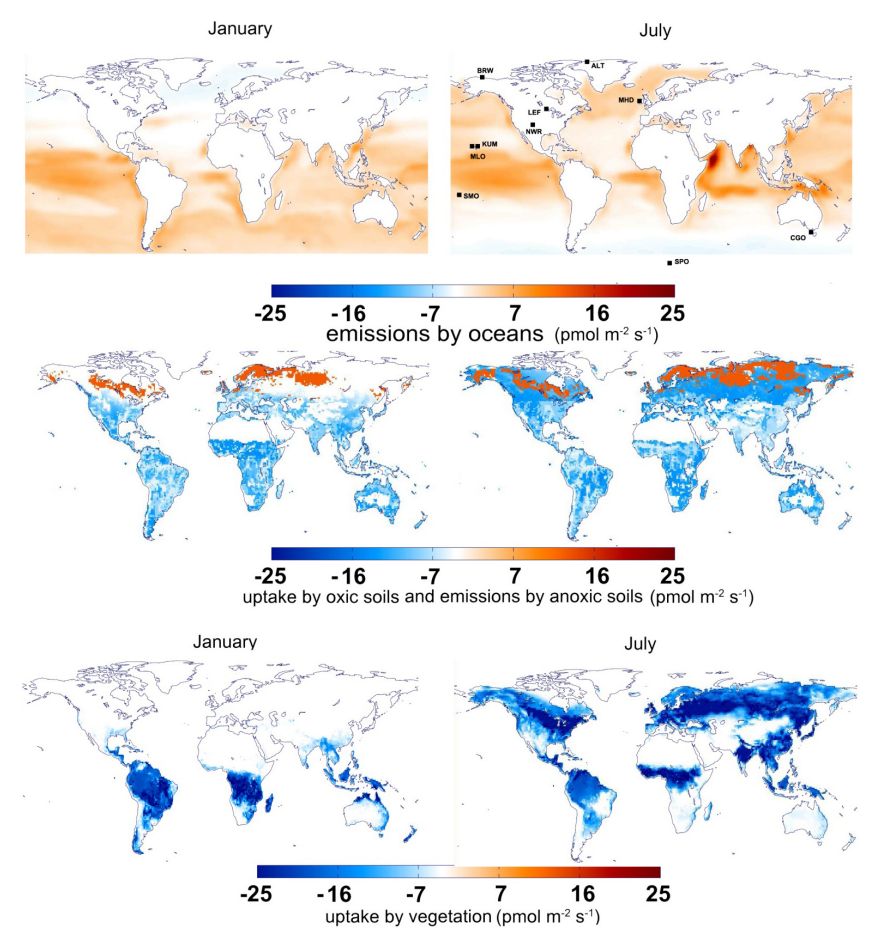

Figure 1. Monthly mean direct oceanic emissions (first row, from the standard run of Launois et al., 2014) for January (left column) and July (right column), monthly mean uptake of OCS by soils (second row, using $\mathrm{H}_{2}$ deposition velocities (Morfopoulos et al., 2012) and OCS to $\mathrm{H}_{2}$ deposition velocities at a 0.75 ratio) and vegetation (third row, deduced from the GPP of ORC). The 10 NOAA stations are SPO, South Pole, $89.9^{\circ} \mathrm{S}, 59^{\circ} \mathrm{E}$; CGO, Cape Grim, Australia, $40.7^{\circ} \mathrm{S}, 144.8^{\circ} \mathrm{E}$; SMO, American Samoa, $14.3^{\circ} \mathrm{S}, 170.6^{\circ} \mathrm{W}$; MLO, Mauna Loa, United States, $19.5^{\circ} \mathrm{N}, 155.6^{\circ} \mathrm{W}$; NWR, Niwot Ridge, United States, $40.1^{\circ} \mathrm{N}, 105.6^{\circ} \mathrm{W}$; BRW, Barrow, United States, $71.3^{\circ} \mathrm{N}, 156.6^{\circ} \mathrm{W}$; ALT, Alert, Canada, $82.5^{\circ} \mathrm{N}, 62.3^{\circ} \mathrm{W}$; MHD, Mace Head, Ireland, $53^{\circ} \mathrm{N}, 10^{\circ} \mathrm{W}$; KUM, Cape Kumukahi, Hawaii, United States, $19.5^{\circ} \mathrm{N}, 154.8^{\circ} \mathrm{W}$ and LEF, Park Falls, Wisconsin, United States, $45.6^{\circ} \mathrm{N}, 90.2^{\circ} \mathrm{W}$.

we scaled the standard direct and indirect emissions within a range of variation of -30 to $50 \%$.

\subsubsection{Leaf uptake of OCS}

OCS and $\mathrm{CO}_{2}$ both diffuse through plant stomata into the leaves. $\mathrm{CO}_{2}$ and OCS are both hydrated in leaves by the carbonic anhydrase enzyme (Protoschill-Krebs and Kesselmeier, 1992; Protoschill-Krebs et al., 1995, 1996; Stimler et al., 2010), following the reactions:

$$
\begin{aligned}
& \mathrm{H}_{2} \mathrm{O}+\mathrm{CO}_{2} \leftrightarrow \mathrm{H}_{2} \mathrm{CO}_{3} \leftrightarrow \mathrm{HCO}_{3}^{-}+\mathrm{H}^{+}, \\
& \mathrm{OCS}+\mathrm{H}_{2} \mathrm{O} \leftrightarrow \mathrm{HCOOS}^{-}+\mathrm{H}^{+} \leftrightarrow \mathrm{H}_{2} \mathrm{~S}+\mathrm{CO}_{2} .
\end{aligned}
$$

Since $\mathrm{HCOOS}^{-}$and $\mathrm{H}_{2} \mathrm{~S}$ are found at very low concentrations in plant cells and soil water (Stimler et al., 2010) and $\mathrm{H}_{2} \mathrm{~S}$ formation is exergonic, thus spontaneous, the hydration of OCS leads irreversibly to the formation of $\mathrm{H}_{2} \mathrm{~S}$ (Schenk 
et al., 2004). Irreversible hydrolysis of OCS is therefore expected within leaves during photosynthesis (Wöhlfahrt et al., 2012; Simmons et al., 1999; Stimler et al., 2010). OCS and $\mathrm{CO}_{2}$ are both potential substrates for RuBisCO, but $\mathrm{CO}_{2}$ is favored over OCS by a factor 110 for species studied by Lorimer and Pierce (1989). Stimler et al. (2010) noted that no significant cross-inhibition was measured between OCS and $\mathrm{CO}_{2}$ uptakes.

Different approaches can be used to model leaf uptake of OCS, from process-based formulations with an explicit representation of diffusion and hydration of OCS as in Berry et al. (2013) to more simple parameterizations where the uptake of OCS is expressed as a linear function of GPP:

$F_{\mathrm{OCS}}=k_{\text {plant_uptake }} \times\left(k_{\mathrm{LRU}} \times \mathrm{GPP}\right)$,

where $k_{\mathrm{LRU}}$ is the leaf relative uptake of OCS compared to $\mathrm{CO}_{2}$ (normalized by their ambient concentrations) and defined for different plant functional type. $K_{\mathrm{LRU}}$ is speciesspecific and several studies have focused on the quantification of this coefficient (Sandoval-Soto et al., 2005, 2012; Stimler et al., 2010; Seibt et al., 2010). We took this latter approach with $K_{\mathrm{LRU}}$ values from Seibt et al. (2010). We also added a global scaling parameter, $k_{\text {plant_uptake, to further op- }}$ timize the relative OCS to $\mathrm{CO}_{2}$ uptake through the inversion scheme. Set to an initial value of $1, k_{\text {plant_uptake }}$ is allowed to vary in the optimization from 0.5 to 1.5 , representing a $\pm 50 \%$ uncertainty range on initial estimate of surface fluxes (Table 1). Note that the $K_{\mathrm{LRU}}$ values from Seibt et al. are in the upper range of recent estimates. A few more details about the implementation of this parameterization can be found in Appendix A2.

\subsubsection{OCS uptake by oxic soils}

The general picture is that oxic soils are a sink of OCS while anoxic soils are a source (Whelan et al., 2013).

OCS uptake by oxic soils is believed to be essentially a microbial and enzymatically driven process with carbonic anhydrase and OCS hydrolases playing central roles (Chin and Davis, 1993a, b; Seibt et al., 2006; Wingate et al., 2008; Ogawa et al., 2013). There are also clear indications that OCS soil uptake varies according to soil type, temperature and soil water content (Kesselmeier et al., 1999; Van Diest and Kesselmeier, 2008). Previous studies used different approaches based either on temperature and water content (Kettle et al., 2002) or on soil heterotrophic respiration (which tracks microbial activity) and the fraction of water filled pore space (Berry et al., 2013). Here we propose a new approach, based on observed co-variations of OCS and dihydrogen $\left(\mathrm{H}_{2}\right)$ deposition to soils and the existence of global $\mathrm{H}_{2}$ deposition maps. Consequently, OCS uptake by soil is represented in our model as

$F_{\mathrm{OCS}}=k_{\mathrm{soil}} \times v_{\mathrm{H}_{2}} \times v_{-\cos \_} v_{\mathrm{H}_{2}} \times[\mathrm{OCS}]_{\mathrm{atm}}$, where $v_{\mathrm{H}_{2}}$ is the deposition velocity of $\mathrm{H}_{2}$ into the soil $\left(\mathrm{cm} \mathrm{s}^{-1}\right), v_{-}{ }_{c o s} \nu_{\mathrm{H}_{2}}$ the relative ratio of OCS and $\mathrm{H}_{2}$ deposition velocities and $[\mathrm{OCS}]_{\text {atm }}$ the atmospheric concentration of OCS (in ppt). $v_{\cos } / v_{\mathrm{H}_{2}}$ was set to an initial value of 0.75 in the standard run (following Belviso et al., 2013, and H. Chen et al., personal communication, 2014). As for leaf uptake, a scaling parameter, $k_{\text {soil }}$, is added to optimize the global uptake of OCS by soils. Details about the overall approach and the global $\mathrm{H}_{2}$ deposition fluxes (taken from a model simulation (Morfopoulos et al., 2012) for our standard simulations and from Bousquet et al. (2011) for tests) can be found in Appendix A3. Given the uncertainties associated with the $v_{\mathrm{H}_{2}}$ estimates and the ratio $v_{\cos } / v_{\mathrm{H}_{2}}$ the surface fluxes were further optimized with a $30 \%$ range of variation for $k_{\text {soil }}$ coefficient (Table 3).

\subsubsection{Release of OCS from anoxic soil and wetlands}

The role of soils in the OCS budget was recently reviewed by Whelan et al. (2013), with special attention to anoxic soils. The authors underlined the major influence of soil temperature and flooding on OCS emissions from anoxic soils and wetlands. Therefore, we followed their approach but used a model simulation for the spatial and temporal distributions of anoxic soils (from Wania et al., 2010). More details on this OCS source can be found in Appendix A4. For optimization purposes, we defined a scaling parameter, $k_{\text {anoxic_soil }}$ (set to a prior value of one), that is optimized with an assigned $\pm 30 \%$ variation range (Table 1).

\subsubsection{Other sources and sinks}

Other sources are related to biomass burning and anthropogenic emissions. OCS emissions from biomass burning were simulated from the gridded $\mathrm{CO}_{2}$ emission maps of Van der Werf et al. (2010) (GFEDv3 product) rescaled to a source of $70 \mathrm{Gg} \mathrm{S} \mathrm{yr}^{-1}$, as estimated by Nguyen et al. (1995). The associated uncertainty (maximum range of variation) was set to $\pm 10 \%$. For anthropogenic emissions (both direct and indirect), we took the fluxes proposed by Kettle et al. (2002). These fluxes were attributed a $\pm 10 \%$ maximum variation in the optimization scheme. Additional direct and indirect emissions of OCS from volcanoes were neglected because they are highly uncertain (Belviso et al., 1986).

The removal of atmospheric OCS by OH radicals is also a significant sink of OCS. We used monthly maps of $\mathrm{OH}$ radicals concentration (integrated vertically up to the tropopause) from Hauglustaine et al. (1998), to distribute both horizontally and temporally a total annual atmospheric sink of $100 \mathrm{Gg} \mathrm{S} \mathrm{yr}^{-1}$, as suggested in previous global budgets (Kettle et al., 2002; Berry et al., 2013). This flux was attributed a $\pm 30 \%$ maximum variation in the optimization scheme. 
Table 1. Summary of forward and inverse simulations performed using the LMDZ transport model and specific setups of surface fluxes. We compared three dynamic global vegetation models (DGVMs), carried out a series of sensitivity tests and optimized major fluxes (the allowed range of variations is expressed in percent). ORC stands for ORCHIDEE. CLM4CN stands for NCAR-CLM4. $v_{\mathrm{H}_{2}}$ and $v_{\mathrm{OCS}}$ are the deposition velocities of $\mathrm{H}_{2}$ and OCS.

\begin{tabular}{|c|c|c|c|c|c|}
\hline & & Simulations names & OCS leaf uptake $^{1}$ & OCS uptake by oxic soil ${ }^{2}$ & OCS oceanic emissions \\
\hline \multirow[t]{11}{*}{$\begin{array}{l}\text { FORWARD } \\
\text { RUNS }\end{array}$} & \multirow[t]{2}{*}{$\begin{array}{l}\text { MODEL } \\
\text { INTER- } \\
\text { COMPARISON }\end{array}$} & STD_ORC & GPP from ORC & $\begin{array}{l}v_{\mathrm{H}_{2}} \text { map (Morfopoulos et al., } \\
2012 \text { ) } \\
v_{\mathrm{OCS}} / \nu_{\mathrm{H}_{2}}=0.75\end{array}$ & $\begin{array}{l}\text { Direct: Launois et al. (2015) } \\
\text { Indirect from DMS: Masotti et } \\
\text { al. (2015) } \\
\text { Indirect from } \mathrm{CS}_{2} \text { : Kettle et al. } \\
\text { (2002) }\end{array}$ \\
\hline & & $\begin{array}{l}\text { STD_CLM4CN } \\
\text { STD_LPJ }\end{array}$ & $\begin{array}{l}\text { GPP from CLM4CN } \\
\text { GPP from LPJ }\end{array}$ & & \\
\hline & \multirow[t]{9}{*}{$\begin{array}{l}\text { SENSITIVITY } \\
\text { TESTS }\end{array}$} & TEST_Ocean_ \pm 30 & GPP from ORC & & Increased/Decreased by $30 \%$ \\
\hline & & \multirow[t]{2}{*}{ TEST_Soil_MORF_0.5:1 } & & $\begin{array}{l}\nu_{\mathrm{H}_{2}} \text { map (Morfopoulos et al., } \\
2012 \text { ) }\end{array}$ & \multirow{8}{*}{$\begin{array}{l}\text { Direct: Launois et al. (2015) } \\
\text { Indirect from DMS: Masotti et } \\
\text { al. (2015) } \\
\text { Indirect from } \mathrm{CS}_{2} \text { : Kettle et } \\
\text { al. (2002) }\end{array}$} \\
\hline & & & & $\begin{array}{l}\nu_{\mathrm{OCS}} / \nu_{\mathrm{H}_{2}}=0.5(\mathrm{H} . \text { Chen, } \\
\text { personal communication, 2014) }\end{array}$ & \\
\hline & & \multirow[t]{2}{*}{ TEST_Soil_MORF_1:1 } & & $\begin{array}{l}v_{\mathrm{H}_{2}} \text { map (Morfopoulos et al., } \\
2012 \text { ) }\end{array}$ & \\
\hline & & & & $\begin{array}{l}\nu_{\mathrm{OCS}} / \nu_{\mathrm{H}_{2}}=1 \text { (Belviso et al., } \\
2013 \text { ) }\end{array}$ & \\
\hline & & \multirow[t]{2}{*}{ TEST_Soil_BOUSQ_0.5:1 } & & $\begin{array}{l}v_{\mathrm{H}_{2}} \text { map (Bousquet et al., } \\
2011 \text { ) }\end{array}$ & \\
\hline & & & & $\begin{array}{l}\nu_{\mathrm{OCS}} / \nu_{\mathrm{H}_{2}}=0.5(\mathrm{H} . \text { Chen, per- } \\
\text { sonal communication, 2014) }\end{array}$ & \\
\hline & & \multirow[t]{2}{*}{ TEST_Soil_BOUSQ_1:1 } & & $\begin{array}{l}v_{\mathrm{H}_{2}} \text { map (Bousquet et al., } \\
\text { 2011) }\end{array}$ & \\
\hline & & & & $\begin{array}{l}\nu_{\mathrm{OCS}} / \nu_{\mathrm{H}_{2}}=1 \text { (Belviso et al., } \\
2013 \text { ) }\end{array}$ & \\
\hline \multirow[t]{5}{*}{ OPTIMIZATION } & & OPTIM_H-Er & $\pm 50 \%$ & $50 \%$ & $-30 /+50 \%$ \\
\hline & & OPTIM_L-Er & $\pm 10 \%$ & $\pm 10 \%$ & $\pm 10 \%$ \\
\hline & & OPTIM_LEAF_ONLY & $\pm 50 \%$ & $\pm 10 \%$ & $\pm 10 \%$ \\
\hline & & OPTIM_SOIL_ONLY & $\pm 10 \%$ & $\pm 50 \%$ & $\pm 10 \%$ \\
\hline & & OPTIM_OCEAN_ONLY & $\pm 10 \%$ & $\pm 10 \%$ & $-30 /+50 \%$ \\
\hline
\end{tabular}

${ }^{1}$ LRU values from Seibt et al. (2010) are used in all simulations, sensitivity tests and optimizations. ${ }^{2}$ Note that the OCS emissions by anoxic soils were kept unchanged between the simulations, and attributed a $\pm 30 \%$ variation range in all optimization configurations. All other surface fluxes are either described in the method section or taken directly from Kettle et al. (2002). They are attributed a $\pm 10 \%$ variation range in all optimization configurations.

\subsection{Models used in this study}

\subsubsection{Terrestrial biosphere models}

For the purpose of this study, three independent DGVMs have been used: LPJ, ORCHIDEE (referred as ORC) and CLM4CN. We used the simulated GPP from each model that was performed for the TRENDY inter-comparison experiment (http://dgvm.ceh.ac.uk/) designed to evaluate global carbon budgets and regional trends of the land carbon sinks over the 1990-2009 period. We took the simulated values over the period 2006-2009 where the models were run with the same 11 climate forcing, variable atmospheric $\mathrm{CO}_{2}$ concentrations and fixed land cover (as a first-order analysis). Details about the DGVMs and the simulations can be found in Sitch et al. (2015); additional information is available in Appendix A5.

\subsubsection{Atmospheric transport model}

The simulated mixing ratios were obtained using the global atmospheric circulation model (GCM) of the Laboratoire de Météorologie Dynamique (LMDZ, version 3; Hourdin et al., 2006). The OCS surface fluxes described above are transported in offline mode using the LMDZ transport model, nudged with wind from the European Centre for MediumRange Weather Forecasts (ECMWF) reanalysis. The transport model uses a $3.75^{\circ} \times 2.5^{\circ}$ (longitude $\times$ latitude) horizontal resolution and 19 vertical layers between the surface and the top of the troposphere. LMDZ has been previously used in many tracer transport studies (Chevallier et al., 2010; Carouge et al., 2010a, b). In this study we used precalculated transport fields, corresponding to the sensitivity of the monthly concentration at each site with respect to the daily surface fluxes for all pixels of the transport grid (see Peylin et al., 2005). These pre-calculated sensitivities were derived from the adjoint of the transport model and were multiplied by the surface fluxes to get the atmospheric OCS 


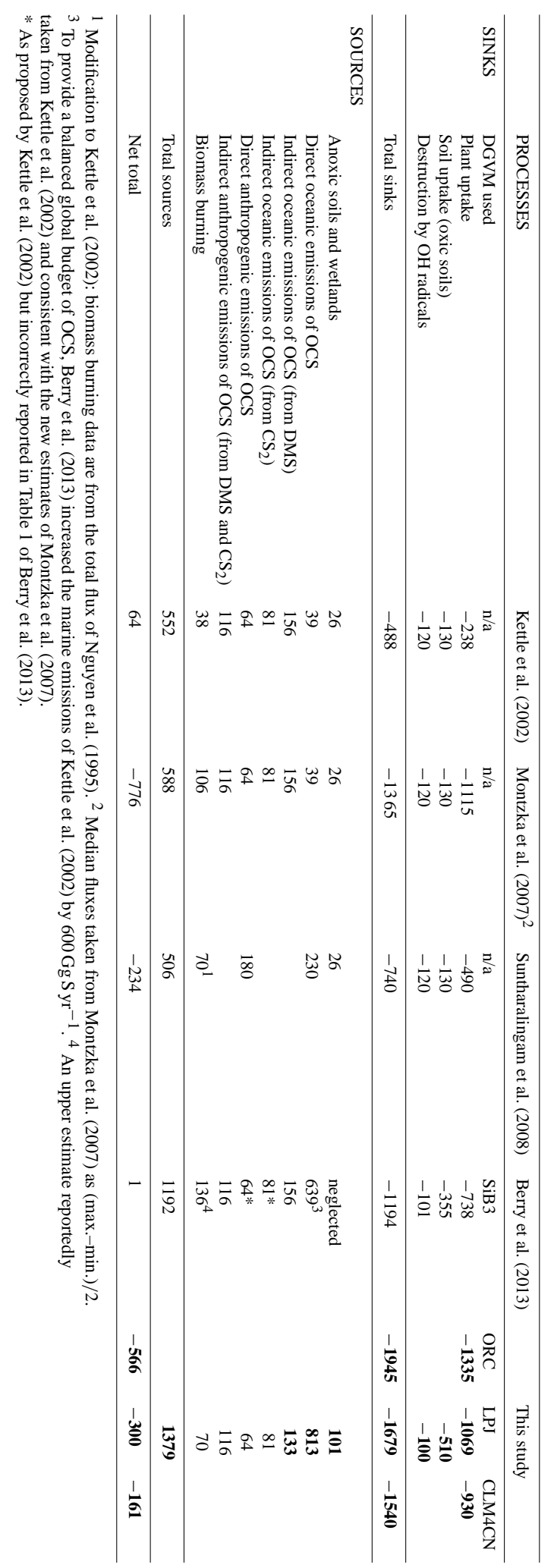

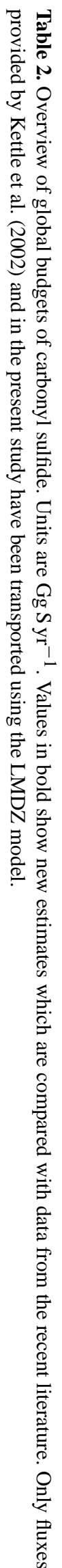


Table 3. OCS surface fluxes before and after their optimization. Units are $\mathrm{Gg} \mathrm{S} \mathrm{yr}^{-1}$. All allowed ranges of variation presented here correspond to the H-Er case (Table 1).

\begin{tabular}{|c|c|c|c|c|c|c|c|}
\hline & \multirow{2}{*}{$\begin{array}{l}\text { PROCESSES } \\
\text { DGVM }\end{array}$} & \multicolumn{3}{|c|}{$\begin{array}{l}\text { Before optimization } \\
\text { Upper and lower limits of variation }\end{array}$} & \multicolumn{3}{|c|}{$\begin{array}{c}\text { After optimization } \\
\text { Adjusted fluxes }\end{array}$} \\
\hline & & ORC & LPJ & CLM4CN & ORC & LPJ & CLM4CN \\
\hline \multirow[t]{2}{*}{ SINKS } & $\begin{array}{l}\text { Plant uptake } \\
\text { Soil uptake (oxic soils) } \\
\text { Destruction by OH radicals }\end{array}$ & {$[-2003,-668]$} & $\begin{array}{c}{[-1604,-0.535]} \\
{[-770,-255]} \\
{[-110,-90]}\end{array}$ & {$[-1395,-465]$} & $\begin{array}{l}-708 \\
-283 \\
-110^{*}\end{array}$ & $\begin{array}{l}-663 \\
-398 \\
-104\end{array}$ & $\begin{array}{l}-772 \\
-507 \\
-110^{*}\end{array}$ \\
\hline & Total sinks & {$[-2883,-1013]$} & {$[-2484,-880]$} & {$[-2275,-8104]$} & -1101 & -1165 & -1389 \\
\hline \multirow[t]{3}{*}{ SOURCES } & $\begin{array}{l}\text { Anoxic soils and wetlands } \\
\text { Direct oceanic emissions of OCS } \\
\text { Indirect oceanic emissions of OCS (from } \\
\text { DMS) } \\
\text { Indirect oceanic emissions of OCS (from } \\
\mathrm{CS}_{2} \text { ) } \\
\text { Direct anthropogenic emissions of OCS } \\
\text { Indirect anthropogenic emissions of OCS } \\
\text { (from DMS and } \mathrm{CS}_{2} \text { ) } \\
\text { Biomass burning }\end{array}$ & & $\begin{array}{c}50,150] \\
{[569,1220]} \\
{[93,173]} \\
{[57,105]} \\
\\
{[58,70]} \\
{[104,128]} \\
{[63,77]}\end{array}$ & & $\begin{array}{l}50^{*} \\
610^{*} \\
93^{*} \\
105^{*} \\
58^{*} \\
104^{*} \\
71\end{array}$ & $\begin{array}{l}50^{*} \\
659 \\
104 \\
105^{*} \\
58^{*} \\
104 * \\
74\end{array}$ & $\begin{array}{l}50^{*} \\
805 \\
173^{*} \\
105^{*} \\
58^{*} \\
104^{*} \\
74\end{array}$ \\
\hline & Total sources & & {$[994,1923]$} & & 1091 & 1154 & 1369 \\
\hline & Net total & {$[-1889,910]$} & {$[-1490,1043]$} & {$[-1281,1113]$} & -10 & -1 & -20 \\
\hline
\end{tabular}

* Surface fluxes which, after optimization, reached the set upper or lower limits of variation. Computed plant and soil uptakes after optimization are on average 714 and $396 \mathrm{Gg} \mathrm{S}$ yr ${ }^{-1}$, respectively

concentration. They will also be directly used in the inversion (see below) as the optimization algorithm requires the sensitivity of the concentrations to the surface fluxes.

\subsection{Optimization framework}

\subsubsection{Principle and setup}

An optimization algorithm was used to correct the surface OCS fluxes in order to improve the simulation of atmospheric OCS temporal and spatial gradients. The optimization scheme relies on a Bayesian framework that accounts for prior knowledge of the surface fluxes (Tarantola, 1987). Each flux has been assigned a scalar coefficient $\boldsymbol{x}$ (see Sect. 2.2) to account for uncertainties in the calculation of the OCS fluxes. These coefficients are the optimized variables (global scaling factors) for all OCS surface flux components described above. Their optimization will provide a better agreement between modeled and observed atmospheric OCS concentrations. The allowed range of variation for each coefficient, $\boldsymbol{x}$, was determined from an analysis of the uncertainties (see Sect. 2.2)

The optimization is based on a 5-year-long simulation covering the 2004-2009 period, long enough to characterize broad atmospheric OCS concentration features (trends and mean seasonal cycles). OCS monthly mean concentrations are used as the observational constraint in the optimization.

\subsubsection{Implementation}

Assuming a Gaussian probability density function (PDF) distribution for the measurement errors, model structure errors (including flux and transport models) and model parameter errors (flux scalars), the optimal set of parameters under the Bayesian framework corresponds to the minimum of the following cost function $J(\boldsymbol{x})$ (Tarantola, 1987):

$$
\begin{aligned}
J(x)= & (\mathbf{Y}-\mathbf{M}(\boldsymbol{x}))^{T} \mathbf{R}^{-1}(\mathbf{Y}-\mathbf{M}(\boldsymbol{x})) \\
& +\left(\boldsymbol{x}-\boldsymbol{x}_{\mathrm{p}}\right)^{T} \mathbf{B}^{-1}\left(\boldsymbol{x}-\boldsymbol{x}_{\mathrm{p}}\right),
\end{aligned}
$$

$\boldsymbol{x}$ represents the parameters to be optimized (i.e., the OCS surface flux scalars), $\boldsymbol{x}_{\mathrm{p}}$ their a priori values, $\boldsymbol{Y}$ the vector of observations (i.e., the measured OCS mixing ratios at NOAA sites), and $\mathbf{M}(\boldsymbol{x})$ the model outputs (i.e., the OCS mixing ratios simulated with the LMDZ transport model). $\mathbf{R}$ and $\mathbf{B}$ are error variances/covariances matrices associated to the observations and the parameters, respectively.

Details about the optimization scheme (gradient-based algorithm with imposed range of variation) as well as the setup of the inversions (uncertainties on the observations and parameters) are presented in Appendix A6. We performed standard optimizations with the OCS leaf uptake derived from each DGVMs and a large range of variation for the scaling parameters but also a few additional sensitivity optimizations summarized in Sect. 2.5.

\subsection{Experiments and data processing}

\subsubsection{Forward simulations for OCS}

A series of simulations was performed, for which the setups are summarized in Table 1 . We carried out three major runs using the three different DGVMs (STD_ORC, STD_LPJ, STD_CLM4CN, see Table 1 for details). We 
made four sensitivity experiments to the representation of soil OCS uptake (with ORC for plant uptake) varying the $\mathrm{H}_{2}$ flux from Morfopoulos et al. (2012) (MORF) to Bousquet et al. (2011) (BOUSQ) and varying the ratio of OCS to $\mathrm{H}_{2}$ uptake as follows: TEST_SOIL_MORF_1:1, TEST_SOIL_MORF_0.5:1, TEST_SOIL_BOUSQ_1:1, TEST_SOIL_BOUSQ_0.5:1. We also undertook two sensitivity experiments varying the magnitude of the oceanic emissions by $\pm 30 \%$ (TEST_OCE_+30 and TEST_OCE_-30). The other surface fluxes were kept unchanged in all sensitivity tests.

\subsubsection{Forward simulations for $\mathrm{CO}_{2}$}

An additional series of simulations was performed to calculate $\mathrm{CO}_{2}$ concentrations at the same stations. The LMDZ transport model was forced with the net ecosystem carbon fluxes from the same three vegetation models (ORC, LPJ, CLM4CN), also using the air-sea exchange from the climatology of Takahashi et al. (2009), biomass burning fluxes from GFEDv3.1 (Van der Werf et al., 2010) and fossil fuel emissions from EDGAR-v4.1 (Marland et al., 1999). Simulations with only the gross ecosystem carbon fluxes (GPP and respiration) were also performed separately, to show the individual impact of the two gross fluxes on the $\mathrm{CO}_{2}$ seasonal cycle at all stations.

\subsubsection{Optimization scenarios for OCS}

Optimization experiments of the surface fluxes (optimization of a scaling coefficient for each OCS flux component; see Sect. 2.4) were conducted, based on the three different vegetation models. For each model, we tested five scenarios (see Table 1):

- OPTIM_H-Er: marine, soil and vegetation fluxes are allowed to vary over a large range (up to $50 \%$ )

- OPTIM_L-Er: marine, soil and vegetation fluxes are allowed to vary over a narrow range $( \pm 10 \%)$ only,

- OPTIM_Leaf_ONLY: only leaf fluxes are optimized with a large range of variation,

- OPTIM_Soil_ONLY: only soil fluxes are optimized with a large range of variation,

- OPTIM_Ocean_ONLY: only ocean fluxes are optimized with a large range of variation.

All other fluxes (OCS oxidation by $\mathrm{OH}$ radicals, emissions from anoxic soils and wetlands, direct and indirect anthropogenic emissions, and emissions from biomass burning) were kept unchanged.

\subsubsection{Data processing and analysis}

Observed and simulated monthly OCS and $\mathrm{CO}_{2}$ concentrations were processed to derive mean seasonal cycles and mean annual trends. To accomplish this, raw data were fitted with a function including a polynomial term (first order) and four harmonics. The residuals of the functions were further smoothed in the Fourier space, using a low-pass filter (cutoff frequency of 65 days) to define a so-called smoothed curve (function plus filtered residuals). The mean seasonal cycle is defined from the smoothed curve after subtraction of the polynomial term. The mismatches between simulated and observed concentrations is also analyzed in terms of bias, phase and variance, following the mean square error (MSE) decomposition of Kobayashi and Salam (2000):

$$
\begin{aligned}
\mathrm{MSE}= & \left(\left\langle X_{i}\right\rangle-\left\langle X_{i^{\prime}}\right\rangle\right)^{2} \\
& +\left(\sigma_{i}-\sigma_{i^{\prime}}\right)^{2}+2\left(\sigma_{i} \times \sigma_{i^{\prime}}\right)(1-r)^{2} .
\end{aligned}
$$

The meaning of the squared data bias is obvious. The second term indicates differences in the fast variability: the lack of correlation $(r)$ between $X_{i}$ and $X_{i^{\prime}}$ is an estimator for phase errors.

\section{Results}

\subsection{Simulated OCS fluxes}

Figure 1 presents the monthly mean emissions and uptakes of OCS by the oceans and the terrestrial biosphere (soils and vegetation) for the months of January and July, as calculated from the new parameterizations presented above. Table 2 describes the corresponding annual fluxes, spatially averaged over oceans and continents.

\subsubsection{Direct oceanic fluxes of OCS}

Following the standard run defined by Launois et al. (2015), oceans emit a yearly total of $813 \mathrm{Gg} \mathrm{S}$ (Table 2). The spatial distribution indicates a large tropical ocean source $(45 \%$ of total OCS emissions). Overall, our simulation provides direct oceanic emissions that are about 20 times larger than those from Kettle et al. (2002) and that are roughly comparable to the estimates from Berry et al. (2013), obtained using an optimization procedure (Table 3). Details about the regional and seasonal distribution of these emissions can be found in Appendix A7.

\subsubsection{Indirect oceanic emissions of OCS}

On a yearly and global basis, the oceans are also a net source of DMS and $\mathrm{CS}_{2}$ to the atmosphere. In NEMO-PISCES, each year $133 \mathrm{Gg} \mathrm{S}$ of OCS are indirectly injected into the atmosphere from DMS, assuming that $0.7 \%$ of the total emissions are converted into OCS. This estimate is in good agreement with that of Kettle et al. (2002). Ocean fluxes of $\mathrm{CS}_{2}$ rely on those of Kettle et al. (2002), since they are not parameterized in NEMO-PISCES. Globally, $\mathrm{CS}_{2}$ indirectly brings $81 \mathrm{Gg} \mathrm{S} \mathrm{yr}^{-1}$ of OCS into the atmosphere, as $87 \%$ of the $\mathrm{CS}_{2}$ 
is assumed to be oxidized into OCS. For more details, see Appendix A7.

\subsubsection{Oxic soil uptake of OCS}

As described in Sect. 2.2, the standard run for oxic soil uptake of OCS is obtained using the $\mathrm{H}_{2}$ monthly soil uptake by Morfopoulos et al. (2012) and 0.75 as the ratio between the deposition velocities of OCS and $\mathrm{H}_{2}$. The resulting OCS fluxes (see Fig. 1 for January and July maps) range between 0 and $15 \mathrm{pmol} \mathrm{m}^{2} \mathrm{~s}^{-1}$; they lead to a global annual uptake of $510 \mathrm{Gg} \mathrm{S}$ (Table 2), which is 3 times larger than the soil uptake modeled by Kettle et al. (2002) and $40 \%$ larger than the one reported by Berry et al. (2013). Using a different $\mathrm{H}_{2}$ flux map (from Bousquet et al., 2011) and ratio between the deposition velocities of OCS and $\mathrm{H}_{2}$ significantly change the global OCS uptake, its regional distribution and its seasonal variations. More details about the regional distribution of the oxic soil uptake can be found in Appendix A7.

\subsubsection{Anoxic soil fluxes of OCS}

The emissions from anoxic soils, as described in Sect. 2.2, mainly take place in the northernmost regions (above $60^{\circ} \mathrm{N}$ ), where fluxes up to $12.5 \mathrm{pmol} \mathrm{m}^{2} \mathrm{~s}^{-1}$ were simulated (Fig. 1). Total emissions are estimated to be $101 \mathrm{Gg} \mathrm{S}$ on an annual basis (Table 2). OCS emissions by peatlands can turn the extratropical regions of the Northern Hemisphere into a net source of OCS in late autumn and winter.

Overall, at a global scale, soils constitute a net sink of OCS. In the Northern Hemisphere, our estimated sink is lower than that of Kettle et al. (2002) and that of Berry et al. (2013) where the OCS emissions by anoxic soils were not taken into consideration. Details of the regional and spatial variations of the net OCS soil fluxes can be found in Appendix A7.

\subsubsection{Plant uptake of OCS}

Global maps of OCS mean uptake by plants for the months of January and July constructed from the GPP of the ORC model are shown in Fig. 1 (bottom). Using ORC, plants take up $1335 \mathrm{Gg} \mathrm{S} \mathrm{yr}^{-1}$ (Table 1), which is a considerably larger sink than that modeled by Kettle et al. (2002) or Berry et al. (2013). This yearly global uptake is strongly model dependent as shown in Table 2 and Fig. S3. Given the linear dependence of OCS uptake to GPP (Eq. 2) the spatial gradients and the phase and amplitude of the seasonal cycle of OCS plant uptake follow those of the GPP. In particular the seasonal cycle shows a distinct peak at high latitudes. Differences between the GPP of the three models are large, especially in terms of amplitude $(60 \%$ difference between the models) and to a small extent in terms of phase of the seasonal cycle (1-month shift) (see Fig. S3 for integrated values over latitudinal bands of the Northern Hemisphere). The main spatial and temporal pattern differences are discussed in Appendix A7.

\subsubsection{Other sources and sinks of OCS}

An OCS sink of about $100 \mathrm{Gg} \mathrm{Syr}^{-1}$ representing photochemical oxidation by $\mathrm{OH}$ radicals was implemented, (see Sect. 2.2). The global annual destruction of OCS is relatively evenly distributed, with seasonal variations higher at high latitudes than in the tropics.

The direct and indirect anthropogenic fluxes were taken from Kettle et al. (2002), who estimated that $180 \mathrm{Gg} \mathrm{S}$ are emitted on an annual basis, without strong seasonal variations. Eastern Asia, eastern Europe and the eastern parts of Canada and the United States concentrate most of the emissions.

As described in Sect. 2.2, the OCS emissions from biomass burning are proportional to the emissions of $\mathrm{CO}_{2}$, and therefore $60 \%$ of the global emissions come from tropical regions.

\subsubsection{Global budget of OCS}

Table 2 provides an overview of the global sources and sinks of OCS. Only Kettle et al. (2002) and Berry et al. (2013) have provided balanced budgets between sources and sinks, but it is worth remembering that Berry et al. (2013) artificially increased the marine emissions of Kettle et al. (2002) by $600 \mathrm{Gg} \mathrm{S} \mathrm{yr}^{-1}$ for this purpose. Other global budgets, including ours, are largely unbalanced, with sinks exceeding sources by hundreds of $\mathrm{Gg} \mathrm{S} \mathrm{yr}^{-1}$. The budget of Montzka et al. (2007) and the one we derived using ORC's GPPs are the most unbalanced ( -776 and $-566 \mathrm{Gg} \mathrm{S} \mathrm{yr}^{-1}$, respectively).

\subsection{Simulated atmospheric OCS concentrations}

We transported the simulated OCS surface fluxes with LMDZ using a forward approach: the resulting global monthly 3-D fields of atmospheric OCS mixing ratios have been compared with in situ observations from the NOAA atmospheric network. Special attention was paid to the annual, seasonal and latitudinal variations of this gas.

\subsubsection{Annual trends}

Figure 2 compares the simulated monthly mean atmospheric OCS concentrations with the observations at Mauna Loa (MLO), a mid-latitudinal background station in the middle of the tropical Pacific Ocean $\left(20^{\circ} \mathrm{N}\right.$, altitude $\left.3500 \mathrm{~m}\right)$. This site therefore represents the integrated contribution of the surface fluxes from the entire Northern Hemisphere (Conway et al., 1994). Since the three global budgets (with the three DGVMs) are not balanced with large sinks (Table 2), the simulations show large negative annual trends of the atmospheric OCS concentrations ( 23 to $70 \mathrm{ppt} \mathrm{yr}^{-1}$ ), which are inconsistent with the observations. Kettle et al. (2002) proposed a 


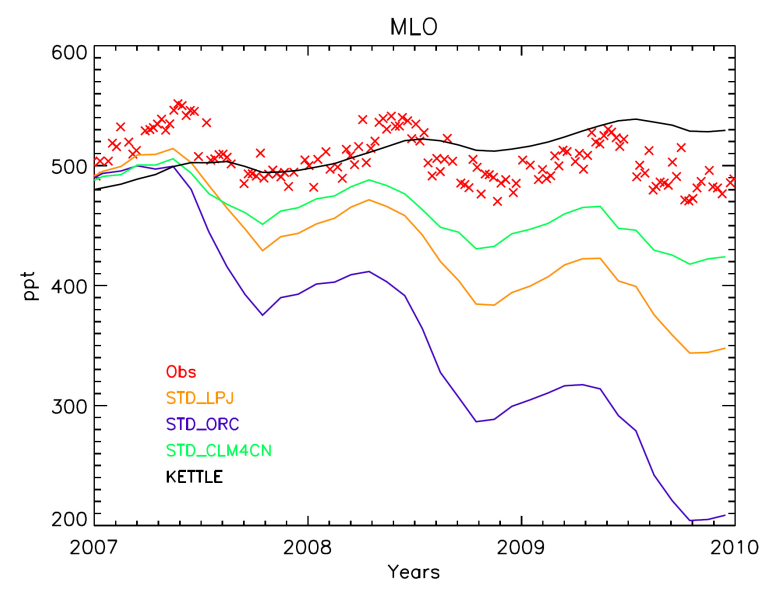

Figure 2. Annual variations of OCS monthly mean mixing ratios (in ppt), simulated and monitored at Mauna Loa. Simulations with the LMDZ model use the STD_ORC, STD_LPJ and STD_CLM4CN configurations described in Table 1. Data derived solely from the Kettle et al. (2002) surface fluxes are shown by the black solid line. Observations (red crosses) are from the NOAA/ESRL global monitoring network (Montzka et al., 2007).

roughly balanced OCS budget but with too small seasonal variations when compared with the observations. The situation at South Pole (SPO) resembles that at MLO in terms of annual trends (Fig. 3)

Results of sensitivity tests on the ocean OCS source (see Sect. 2.5) are displayed in Fig. 3. Changing the ocean source significantly (by $\pm 30 \%$ ) impacts the simulated trend and only marginally the phase and amplitude of the seasonal cycle (except at SPO). In the case of ORC, the test TEST_OCE_+30 provides a global budget close to equilibrium.

Figure 4 (left panel) shows the impact on the annual trend at MLO of four sensitivity tests on the calculation of oxic soils OCS uptake (see Sect. 2.5). The annual trend is more af-

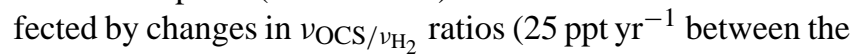
$1: 1$ and $0.5: 1$ ratios) than by changes in the way $\mathrm{H}_{2}$ deposition velocities have been estimated $\left(10 \mathrm{ppt} \mathrm{yr}^{-1}\right.$ difference between the TEST_SOIL_MORF and TEST_SOIL_BOUQ simulations). However, changes in OCS uptake by oxic soils cannot compensate entirely for the strong negative trend imposed by the vegetation sink deduced from ORC GPP.

\subsubsection{Simulated phase and amplitude of the seasonal variations}

Figure 5 (right panels) compares the smooth seasonal cycle of OCS concentrations of three different simulations, the concentrations deduced from Kettle inventory and the observations at the South Pole (SPO), Alert (ALT) and MLO stations. The ALT data help in exploring the influence of boreal and temperate ecosystems of the Northern Hemisphere on the biogeochemical cycle of OCS, while SPO station combines the southern ocean and land influences. The simulation based on Kettle et al. (2002) fluxes exhibits amplitudes which are unrealistically low and not in phase with the observations at ALT and MLO. At SPO, on the contrary, Kettle et al. (2002) fluxes produce a good fit to the observations, both in terms of seasonal amplitude and phase. At SPO, our three models simulate slightly larger amplitudes $(+10-15 \mathrm{ppt}$ relative to observations) and a slight shift in the OCS maximum during austral summer.

The ORC model displays the highest seasonal amplitudes both at ALT and MLO where the northern vegetation influence dominates seasonal variations (around 250 and $80 \mathrm{ppt}$, respectively). These variations are unrealistically high compared to the observations (100 and $55 \mathrm{ppt}$, respectively). However, ORC shows seasonal OCS variations more in phase with the observations than when using the two other DGVMs' GPP, especially at ALT. Using CLM4CN leads to the right amplitude of the seasonal variations in OCS concentrations at ALT, but the phase is incorrectly represented (earlier OCS build-up and draw-down). This model provides a better representation of the phase of the OCS cycle at MLO but leads to a $10 \%$ underestimation of the OCS seasonal amplitude at this station. With the data shown in the right panels of Figs. 3 and 4, we aim to characterize the sensitivity of seasonal variations to changes solely in marine emissions and in the soil sink, respectively (following sensitivity experiments described in Sect. 2.5). At MLO, both the phase and the amplitude of the seasonal variations are unaffected by changes in marine emissions (Fig. 3) or oxic soils uptake (Fig. 4). At SPO, a $30 \%$ increase of the ocean flux leads to about $10 \%$ increase in amplitude of the seasonal variations (Fig. 3). Similar experiments were conducted to evaluate the contribution of plant uptake on the overall seasonality of atmospheric OCS (runs where only the plant uptake is transported). Figure 6 shows that the amplitude and the phase of the seasonal variations at ALT and MLO are both primarily determined by the uptake of OCS by vegetation. On the other hand, plant uptake plays a minor role on the seasonality at SPO.

\subsubsection{Annual mean atmospheric concentrations of OCS: north-south gradients}

Annual mean mixing ratios for the 10 stations of the NOAA monitoring network, plotted as a function of latitude, are shown in Fig. 7. Note that the simulated global mean OCS concentration (across all sites) has been rescaled to the observed global mean, so that only the gradients between stations should be investigated. The main results from this hypothesis are

1. Our new OCS surface flux scenarios capture the main differences in annual mean concentration between stations with lower concentrations at continental stations in the Northern Hemisphere (LEF, BRW, ALT) than 

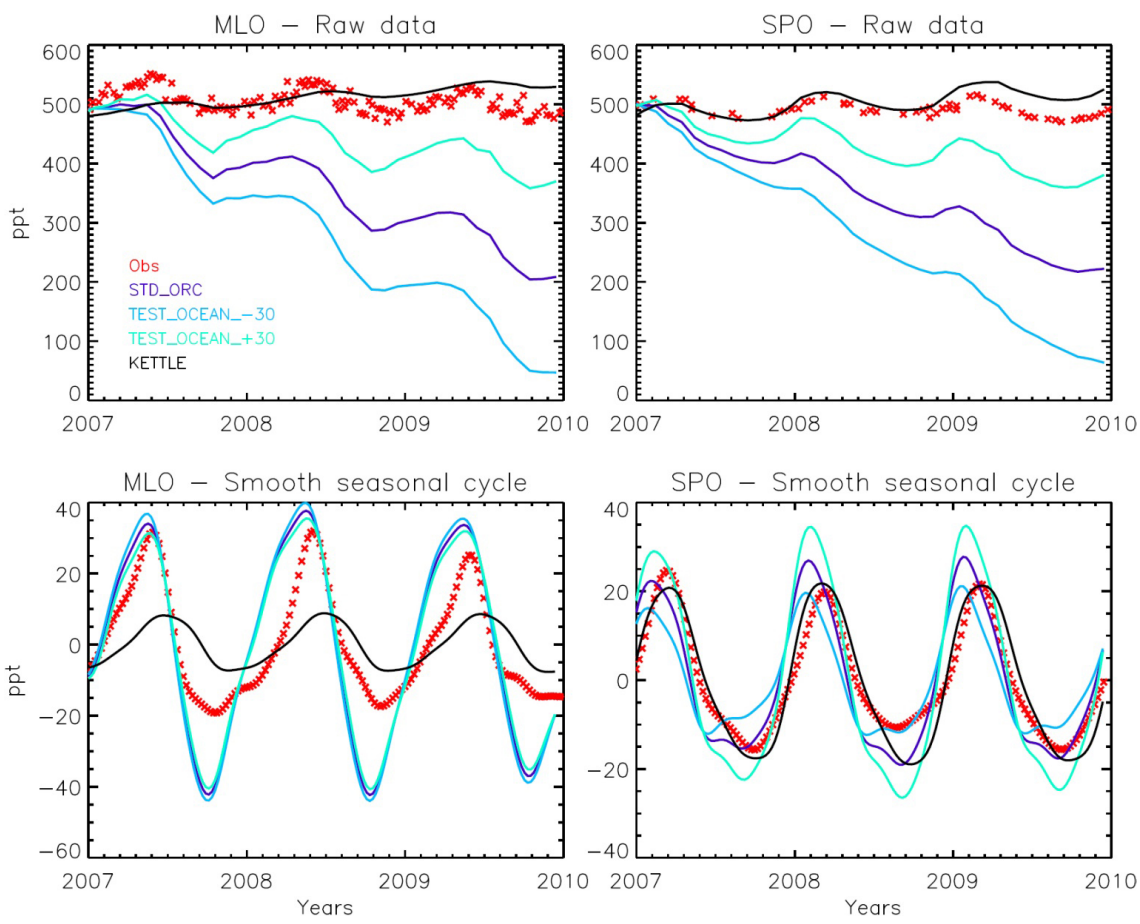

Figure 3. Sensitivity tests performed using the TEST_Ocean_ \pm 30 setup of surface fluxes (Table 1) to simulate the annual variations of OCS monthly mean mixing ratios (upper panels) simulated and monitored at Mauna Loa (left column) and South Pole (right column). Raw data were fitted with a function including a polynomial term (first order) and four harmonics. The residuals of the functions were further smoothed in the Fourier space, using a low-pass filter (cutoff frequency of 65 days) to define a so-called smoothed curve (function plus filtered residuals). The mean seasonal cycle is defined from the smoothed curve after subtraction of the polynomial term. The corresponding smoothed seasonal variations obtained are displayed in lower panels. The simulations based solely on the Kettle et al. (2002) surface fluxes are shown with a black solid line. Observations (red crosses) are from the NOAA/ESRL global monitoring network (Montzka et al., 2007).
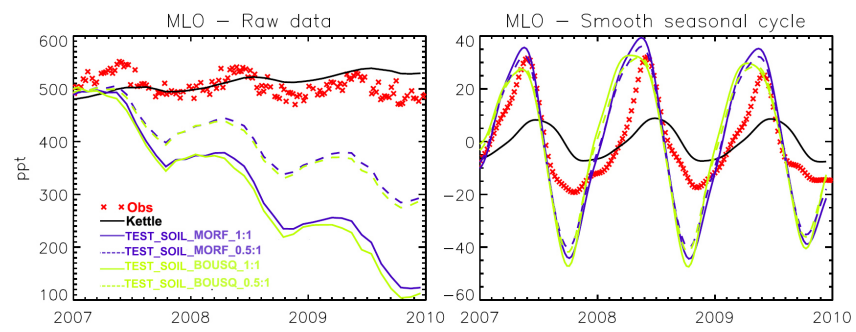

Figure 4. Sensitivity tests performed using the TEST_Soil_MORF_0.5:1, TEST_Soil_MORF_1:1, TEST_Soil_BOUSQ_0.5:1 and TEST_Soil_BOUSQ_1:1 setups of surface fluxes (Table 1) to simulate annual variations of OCS monthly mean mixing ratios (left panel) and smoothed seasonal variations obtained after removing the annual trends (right panel), at Mauna Loa. The simulations based solely on the Kettle et al. (2002) surface fluxes are shown by the black solid line. Observations (red crosses) are from the NOAA/ESRL global monitoring network (Montzka et al., 2007). at background stations as in the Southern Hemisphere (around $50 \mathrm{ppt}$ lower).

2. Observed differences between southern extratropical marine stations and tropical marine stations (higher concentration over the tropics by $10 \mathrm{ppt}$ ) are also represented by the different scenarios.

3. Significant discrepancies still affect all scenarios, such as for instance, the difference between NWR and LEF, with simulated values around 25 to $30 \mathrm{ppt}$ compared to observed ones around $60 \mathrm{ppt}$.

4. There are small but significant differences between the three scenarios based on three different ecosystem models. For instance, between Cape Grim (CGO) and American Samoa (SMO), although all models largely overestimate the mean concentration gradient, using CLM4CN reduces it by nearly $20 \mathrm{ppt}$ compared to ORC. Similarly, CLM4CN gives a lower annual mean concentration at Point Barrow (BRW) than at Alert (ALT) while the two others models give higher concentrations at BRW, in line with the observations. 

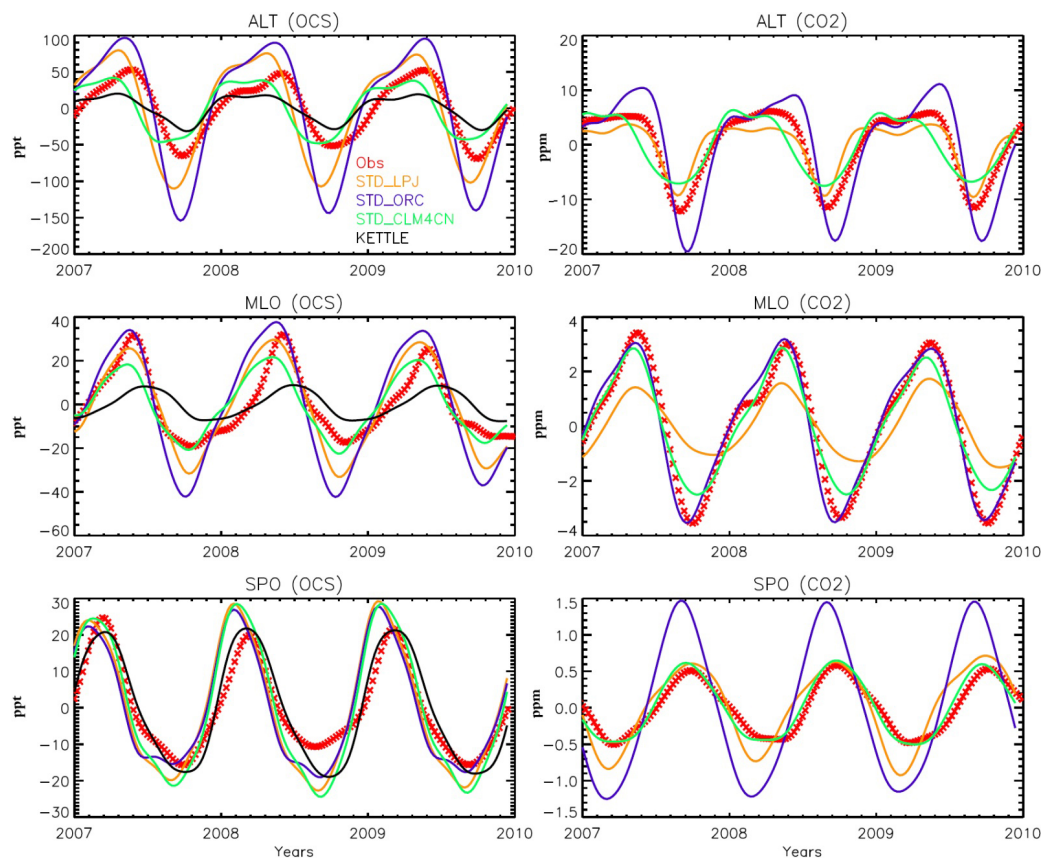

Figure 5. Smoothed seasonal cycles of OCS (left column) and $\mathrm{CO}_{2}$ (right column) monthly mean mixing ratios, simulated at ALT, MLO and SPO, and obtained after removing the annual trends. Simulations obtained with the LMDZ model using the STD_ORC, STD_CLM4CN, STD_LPJ setups (Table 1). Data derived solely from the Kettle et al. (2002) surface fluxes are shown by the black solid line. Observations (red crosses) are from the NOAA/ESRL global monitoring network (Montzka et al., 2007).
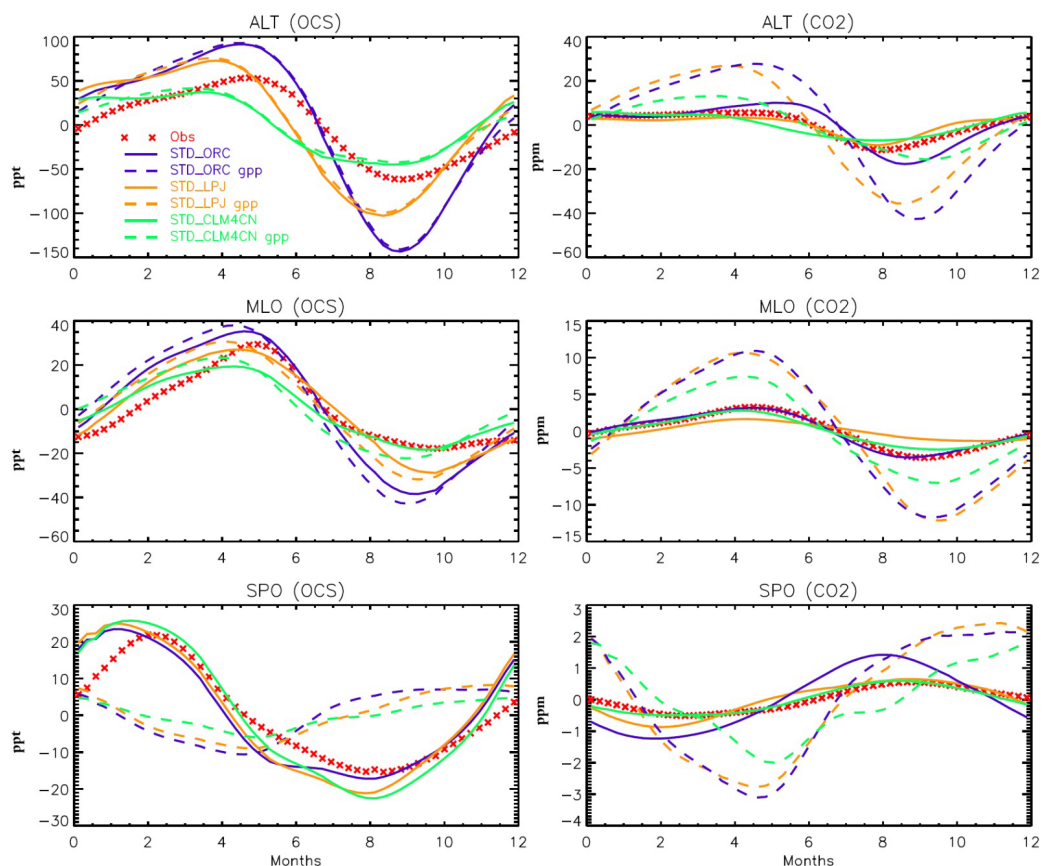

Figure 6. Average smoothed seasonal cycles of OCS (left column) and $\mathrm{CO}_{2}$ (right column) monthly mean mixing ratios, simulated at ALT, MLO and SPO, and obtained after removing the annual trends. OCS cycles simulated with the LMDZ model using the STD_ORC, STD_LPJ and STD_CLM4CN setups (Table 1). The dashed lines represent the smoothed seasonal cycles of the OCS (left column) and $\mathrm{CO}_{2}$ (right column) monthly mean mixing ratios when only the contribution of the leaf OCS uptake (or GPPs) of the three vegetation models are used in the LMDZ transport model (ORC gpp, CLM4CN gpp and LPJ gpp). Observations (red crosses) are from the NOAA/ESRL global monitoring network (Montzka et al., 2007). 


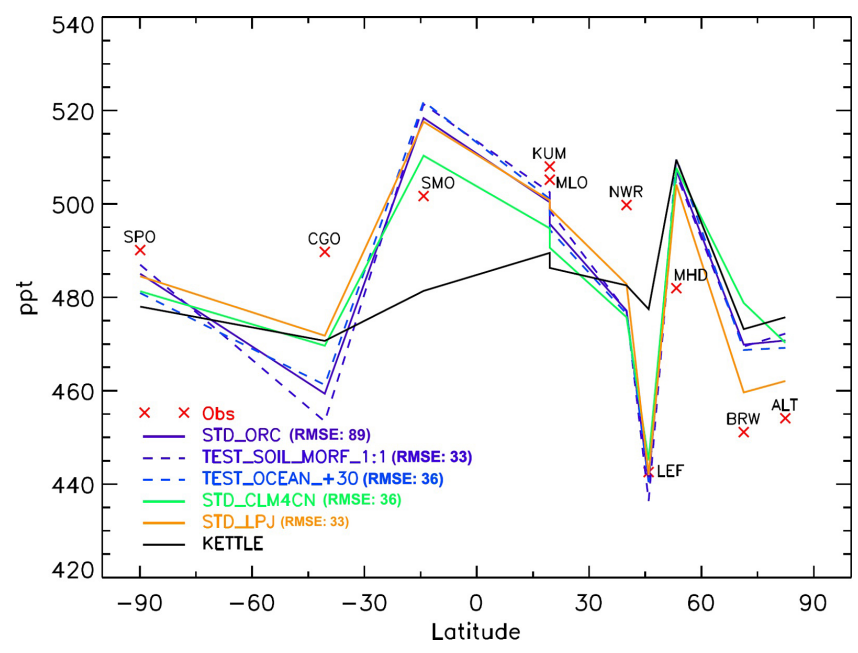

Figure 7. Differences in OCS annual mean mixing ratios between 10 stations of the NOAA monitoring network, plotted as a function of latitude, for observations (red crosses surmounted by station acronyms) and simulations (no symbol). Note that the global mean for each mixing ratio series has been set to the global mean of the observations. Simulations obtained with the LMDZ model using the STD_ORC, STD_CLM4CN and STD_LPJ setups (Table 1). Data derived solely from the Kettle et al. (2002) surface fluxes are shown by the black solid line. The sensitivity of latitudinal gradients to changes in soil uptake and ocean emissions (dashed colored lines) was investigated using the TEST_Soil_MORF_1:1+30\% and TEST_Ocean_+30\% setups.

5. The simulation based on the Kettle et al. (2002) fluxes shows much smaller annual mean gradients across stations than our three scenarios. The better match between the observed gradients and our new flux scenarios partly arises due to the re-estimated high oceanic emissions in the tropical regions.

The two sensitivity tests, where ocean emission and soil uptake were increased by $30 \%$ (TEST_OCEAN_+30 and TEST_SOIL_MORF_1:1, respectively), have little influence on the atmospheric mixing ratios when compared with the STD_ORC run (Fig. 7, dotted and dashed lines).

\subsection{Results of the optimization: OCS concentrations and surface fluxes}

Each surface flux component has been scaled with an optimization procedure (see Sects. 2.4 and 2.5) in order to obtain the best fit to the atmospheric OCS concentrations (raw data). We investigate whether the observed temporal and spatial OCS variations can be matched through the optimization and highlight corrections on the GPP and other fluxes that would be needed. Table 3 summarizes the initial and the optimized values of the surface fluxes for the different optimization configurations.

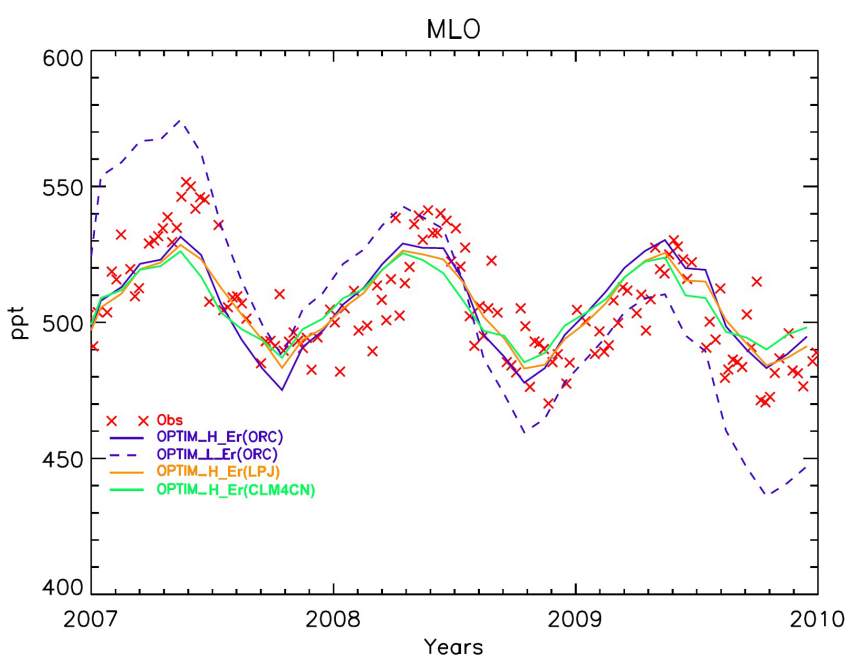

Figure 8. Annual variations of OCS monthly mean mixing ratios (in ppt), optimized and monitored at Mauna Loa. Simulations obtained with the LMDZ model using the OPTIM_H-Er setup (Table 1) applied to ORC, NCAR-CLM4 and LPJ models. Observations (red crosses) are from the NOAA/ESRL global monitoring network (Montzka et al., 2007). A sensitivity test was carried out using ORC and the OPTIM_L-Er setup (dashed blue line).

\subsubsection{Optimization of the annual trends}

The OCS monthly mean concentrations simulated with the optimized surface fluxes of the OPTIM_H-Er scenario (large range of variation for the optimized parameters) are shown in Fig. 8. Allowing a $50 \%$ range of variation on the surface fluxes is sufficient to yield equilibrated global budgets after optimization, in agreement with the observations (see the last line of Table 3). Overall, the total sink is decreased in all optimization results, from an average value (all three DGVMs included) of $1721 \mathrm{Gg} \mathrm{S} \mathrm{yr}^{-1}$ in the prior simulation to $1218 \mathrm{Gg} \mathrm{S} \mathrm{yr}^{-1}$ after optimization, thus a $29 \%$ reduction. The source flux estimates were also reduced by $13 \%$ on average, from $1379 \mathrm{Gg} \mathrm{S} \mathrm{yr}^{-1}$ in the prior simulation to $1204 \mathrm{Gg} \mathrm{S} \mathrm{yr}^{-1}$ after the optimization. The new simulated global budgets are almost balanced ( -1 to $-20 \mathrm{Gg} \mathrm{S} \mathrm{yr}^{-1}$ ) and the annual trend significantly reduced (Fig. 8 versus Fig. 2), especially for ORC ( -566 to $-10 \mathrm{Gg} \mathrm{S} \mathrm{yr}^{-1}$ ).

The soil uptake of OCS is reduced as much as $45 \%$ even if the maximum range of variation allowed is $50 \%$. The leaf uptake of OCS is also not reduced by the maximum amount when given a variation limit of $50 \%$. On average, vegetation and soil optimized uptakes are respectively converging around 714 and $396 \mathrm{Gg} \mathrm{S} \mathrm{yr}^{-1}$ (Table 3). The atmospheric destruction of OCS by $\mathrm{OH}$ radicals and some sources were also optimized at their maximum allowed values (e.g., emissions by anoxic soils, indirect oceanic emissions and indirect anthropogenic emissions).

In the low variation range scenario (OPTIM_L-Er), a negative trend of about $30 \mathrm{ppt} \mathrm{yr}^{-1}$ remains in ORC (Fig. 8). This 
OPTIM_L-Er configuration could be thought as a theoretical case where the values of $k_{\mathrm{LRU}}$ (for OCS leaf uptake) are well constrained and the fluxes are controlled by soil, ocean and anthropogenic processes. In this theoretical case, the mismatch between the simulated and observed annual trend for ORC suggests that

1. the vegetation plays a determining role in the OCS global atmospheric budget

2. the leaf uptake of OCS is too large when using ORC, highlighting a too large global annual GPP flux.

In reality, the LRU values (taken from Seibt et al., 2006) are likely to be too large so that the conclusion on the GPP of ORC cannot be inferred yet with the OCS budget only.

\subsubsection{Optimization of the amplitude and phase of the seasonal variations}

Figure 9 shows the OCS mean seasonal cycles before and after optimization using the three DGVMs. At most NOAA stations, the optimization of the surface fluxes significantly improves the simulated seasonal amplitude of the atmospheric OCS concentrations, with a global reduction of the MSE (in $\mathrm{ppt}^{2}$ ) from 162 (83) to 29 (29) ppt for ORC (LPJ) and from 43 to $35 \mathrm{ppt}$ for CLM4CN. Although all optimizations lead to a significant improvement of the amplitude of the OCS cycle, differences between the three models remain:

1. With the ORC model, the standard OPTIM_H-Er configuration strongly reduces the amplitude of the simulated OCS seasonal cycle, especially at high latitudes (e.g., from 225 to $140 \mathrm{ppt}$ at ALT). The resulting amplitudes are more consistent with the observations but are still too large at high latitudes (140 versus $100 \mathrm{ppt}$ at ALT). At MLO, the amplitude of the OCS levels is reduced from 80 to $45 \mathrm{ppt}$, a value slightly lower than the observations (50 ppt). Finally, we also note that scaling the surface fluxes through the optimization leads to negligible modifications of the phase of the simulated OCS concentrations.

2. With LPJ, the optimization also leads to a reduction of the sources and sinks (Table 3), which decreases the amplitude of the OCS seasonal cycle. Among the three DGVMs, LPJ displays the best fit of the amplitude of the OCS annual cycle at temperate latitudes with the observations. However, the optimization does not improve the phase of the atmospheric OCS signal with, therefore, the same 2-month-early shift of the model at northern stations (ALT and BRW) as for ORC.

3. With CLM4CN, the optimization does not significantly improve the mean seasonal cycle, with too small prior and posterior amplitudes at high northern sites compared to the observations (60 and $75 \%$ of the observed cycle amplitude at ALT and MLO, respectively). The phase is also not changed and most discrepancies noted in Sect. 3.2.2 remain (e.g., 2-month phase advance at BRW).

Overall the three final sets of optimized fluxes (Table 3) confirm that

1. The total sink is always reduced, mainly through a decrease of soil uptake and plant uptake.

2. The large direct emissions of OCS by the tropical oceans are decreased by only $15 \%$, with global annual mean around $691 \mathrm{Gg} \mathrm{S} \mathrm{yr}^{-1}$ (after optimization)

3. New vegetation and soil uptakes, respectively, around 714 and $396 \mathrm{Gg} \mathrm{S} \mathrm{yr}^{-1}$ (Table 3) would be needed for fitting the main temporal and spatial variations of atmospheric OCS. These new estimates are in the upper range of previously published global budgets (Table 2).

\subsubsection{Optimization of the annual mean north south gradients}

Figure 10 presents annual mean OCS mixing ratios at all stations as a function of the latitude before and after optimization. The overall improvements from the optimization are summarized with the mean of the MSE for all sites (see the legend). Posterior MSEs are similar between the three scenarios (around $24 \mathrm{ppt}^{2}$ ) and the reduction between the prior and the posterior MSEs are equivalent to 74, 31 and $27 \%$ for ORC, CLM4CN and LPJ respectively. Note that such improvement is much smaller than for the seasonal cycle where MSE decreases by 82, 19 and 65\%, respectively (see Fig. 9). The large reduction of the soil and leaf OCS uptakes through the optimization (see Table 3 ) helps reducing initial differences in the spatial gradients between stations. For example, the simulated difference between SPO and CGO stations in the Southern Hemisphere drops from $10-25$ to $2-10 \mathrm{ppt}$ in closer agreement with the observations (around $1 \mathrm{ppt}$ ).

\section{Discussion}

Although our revised OCS budgets agree relatively well with the observed temporal and spatial gradients recorded at NOAA stations (using the LMDZ transport model), other biases still exist. These biases will be first discussed to highlight potential errors in the OCS leaf, soil and ocean surface fluxes. In a second step, we will review and discuss the constraint brought by OCS on the GPP of the three tested DGVMs, when the information from both OCS and $\mathrm{CO}_{2}$ tracers are combined. 

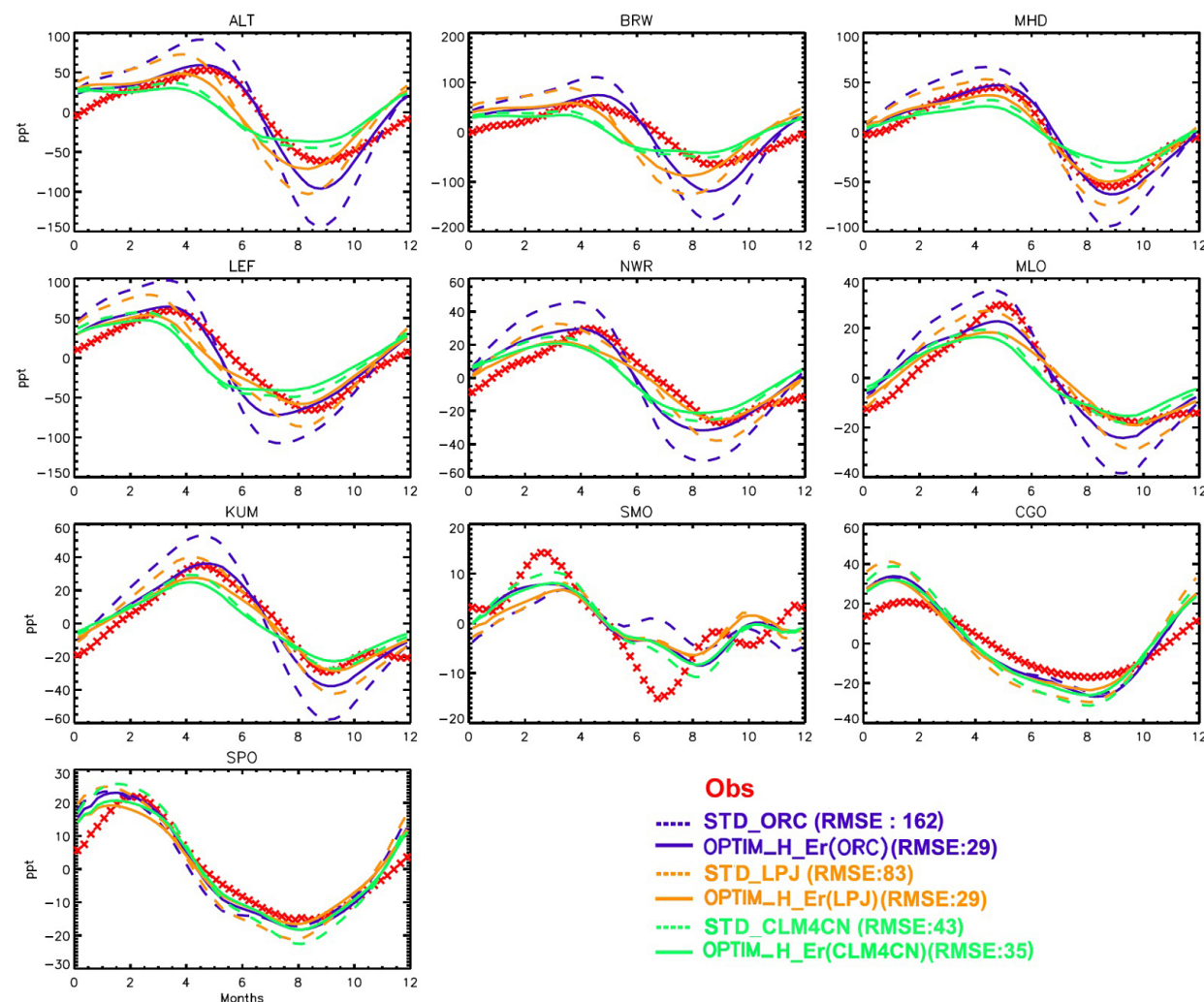

\section{Obs}

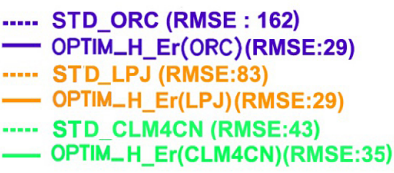

Figure 9. Smoothed seasonal cycles of OCS monthly mean mixing ratios, simulated at 10 stations of the NOAA monitoring network, and obtained after removing the annual trends. Forward simulations with the LMDZ model use surface fluxes from the STD_ORC, STD_CLM4CN and STD_LPJ setups (dashed lines). The OPTIM_H-Er setup (Table 1) was used in the optimizations (solid lines). Observations (red crosses) are from the NOAA/ESRL global monitoring network (Montzka et al., 2007). Global root mean square errors (RMSEs) are given in the legend.

\subsection{Remaining biases in simulated atmospheric OCS concentrations}

The standard optimizations (OPTIM_H-Er) using the three DGVMs provide an equilibrated atmospheric budget, with fluxes for the three most important OCS surface processes converging to similar values (Table 3 ) across all simulations: leaf and soil mean annual uptake are 714 and $396 \mathrm{Gg} \mathrm{S} \mathrm{yr}^{-1}$ respectively, and ocean release is $691 \mathrm{Gg} \mathrm{S} \mathrm{yr}^{-1}$. These values are much larger than those proposed initially by Kettle et al. (2002) and relatively close to the recent budget of Berry et al. (2013). Large gross surface fluxes are needed to simulate the observed seasonal peak-to-peak amplitude at the mid-/high latitudes of the Northern Hemisphere (around $120 \mathrm{ppt}$ ), as highlighted by the optimizations. Note that the study of Berry et al. (2013) further emphasizes the need for large land surface uptake (leaf and soil) if we are to simulate the observed vertical profiles over vegetated areas (especially the observed drawdown of OCS concentrations in boundary layers; see their Fig. 9). On average our ensemble of tests highlights for all three scenarios that (i) uptake through leaves (following GPP) controls the atmospheric seasonal cycle, and (ii) uptake by oxic soils, although the second largest sink, has a limited impact on the atmospheric OCS seasonal cycle.

Below, we summarize the performances of different optimization scenarios (based on the three DGVMs) and highlight the remaining discrepancies in terms of simulated trend, amplitude and phase of the seasonal cycle. Figure 11 displays the observed minus modeled trend at MLO (first row), the mean square error (MSE) decomposition (phase, bias and variance; see Sect. 2.5, Eq. 3) obtained from the detrended concentrations at ALT and MLO (second and third row) and the amplitude of the seasonal cycle at ALT and MLO (last two rows). The results from several optimization scenarios (based on the three DGVMs) are displayed including prior fluxes (Pri), optimized fluxes with high and low uncertainties (OPTIM_H-Er and OPTIM_L-Er), and three tests where only the leaf, soil or ocean component are optimized (the other components being fixed).

\subsubsection{Atmospheric trends}

As shown in Fig. 11, the optimization successfully corrects the annual trends, for most scenarios. For ORC, the global budget is closed only if the leaf uptake is decreased by $45 \%$, 


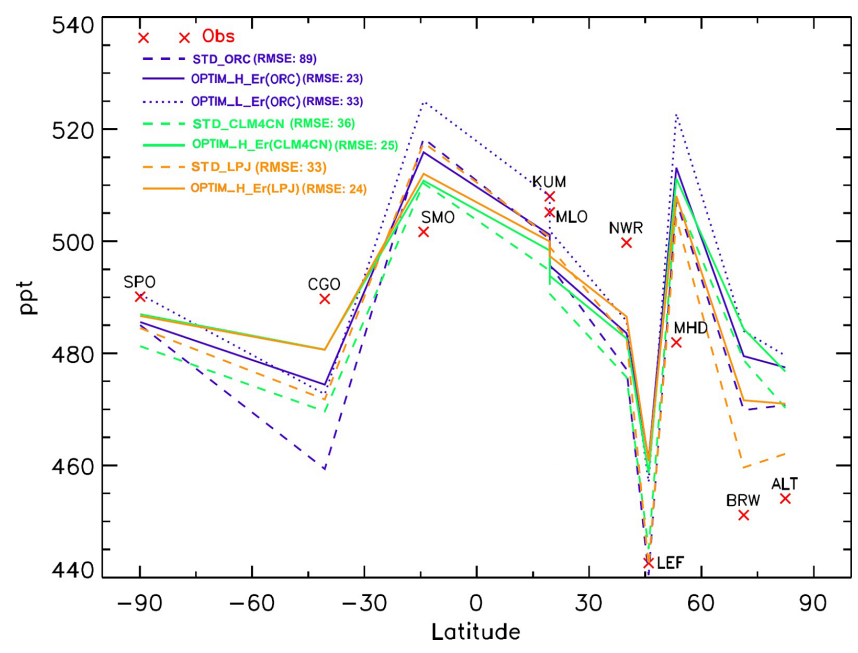

Figure 10. Differences in OCS annual mean mixing ratios between 10 stations of the NOAA monitoring network, plotted as a function of latitude, for observations (red crosses surmounted by station acronyms) and simulations (no symbol, forward approach (colored dashed lines), inverse approach (colored solid lines)). Forward simulations with the LMDZ model use the STD_ORC, STD_CLM4CN and STD_LPJ setups (dashed lines). The OPTIM_H-Er setup (Table 1) was used in the optimizations (solid lines). A sensitivity test was carried out using ORC and the OPTIM_L-Er setup (blue dotted line). Note that the global mean for each simulation ensemble has been set to the global mean of the observations.

which is not possible in the low error test. This suggests that LRU values provided by Seibt et al. (2010) are likely too large. Future studies would benefit from using lower LRU values, such as those published in other studies (SandovalSoto et al., 2005; Stimler et al., 2012; Berkelhammer et al., 2014). Lower LRU values also correspond to a test in Seibt et al. (2010) where the internal mesophyll conductance is set as the major limitation in the diffusional pathway of OCS (average LRU would be 2.08 with this assumption, instead of 2.8 as used in the present paper). Moreover, several studies have shown that OCS-to- $\mathrm{CO}_{2}$ uptake ratio could be plant-specific (Sandoval-Soto et al., 2005; Campbell et al., 2008; Seibt et al., 2010; Stimler et al., 2012; Berkelhammer et al., 2014) and even that, under certain conditions, some plants can release some of the absorbed OCS (Xu et al., 2001; Geng and $\mathrm{Mu}, 2006$; White et al., 2010). Therefore, recent estimates of the vegetation OCS uptake are still largely uncertain and differ by up to a factor of 6 (Xu et al., 2001; Kettle et al., 2002; Sandoval-Soto et al., 2005; Berry et al., 2013).

1. Optimizing only one flux component is usually enough to correct the trend, except for ORC, pointing out again the likely too high leaf uptake, which can be due to overestimated LRU or too large GPP
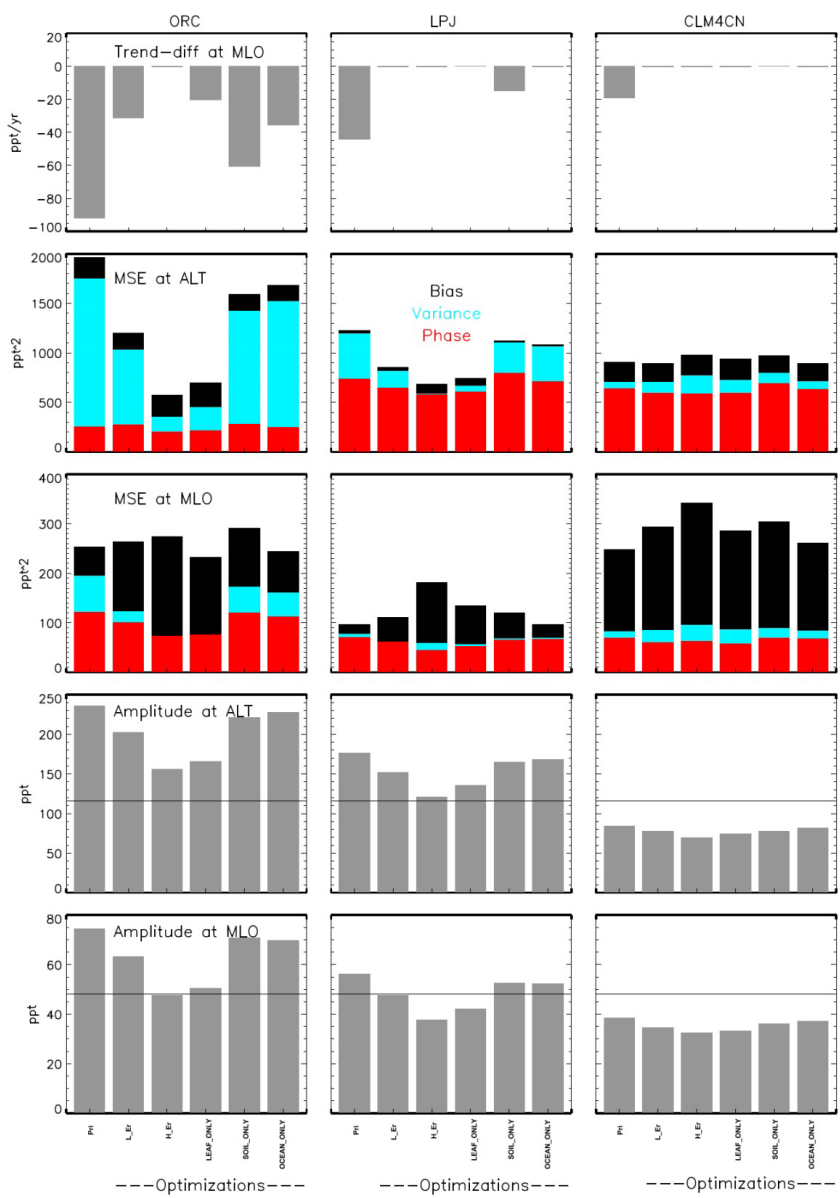

Figure 11. Upper row: differences in annual trends (in ppt $\mathrm{yr}^{-1}$ ) between simulated monthly mean OCS mixing ratios and measurements, at Mauna Loa. Second and third rows: analysis of smoothed seasonal cycles in simulations and observations (at Alert and Mauna Loa, respectively), and calculation of the mean square error (MSE, in $\mathrm{ppt}^{2}$ ) decomposed into three components (bias, phase and variance, as described by Kobayashi and Salam (2000). Fourth and fifth rows: specific analysis of the amplitude of simulated smoothed seasonal cycles, at Alert and Mauna Loa respectively. The horizontal solid line represents the observed value. The bar plots compare the forward approach (Pri using the STD_ORC, STD_LPJ or STD_CLM4CN setups) to the optimization runs (using the OPTIM_H_Er, OPTIM_L_Er, OPTIM_Leaf_ONLY, OPTIM_Soil_ ONLY and OPTIM_Ocean_ONLY setups (Table 1)).

\subsubsection{Phase and amplitude of the atmospheric seasonal cycles}

Looking at the phase component of the MSE decomposition, a few general features can be drawn:

1. On average, only small changes are observed at most sites between prior and posterior estimates (only shown for MLO and ALT, Fig. 11, second and third rows). A $35 \%$ reduction of the phase error is observed at MLO for ORC and also a $25 \%$ improvement for LPJ. 
2. These small phase changes result from the optimization of only one global annual scalar for each flux component.

3. On average, ORC provides, after optimization, the best phase agreement with the observations at high northern latitude stations (see ALT). At MLO the optimized results are closer between the three models, although LPJ and CLM4CN provide slightly better matches with the observations (72 and $70 \mathrm{ppt}^{2}$ error respectively, versus $120 \mathrm{ppt}^{2}$ for ORC).

4. Most changes are due to the optimization of the leaf uptake, while OPTIM_SOIL_ONLY and OPTIM_OCEAN_ONLY configurations do not allow for significant phase improvement.

5. Further improvement of the phase should account for potential variations of LRU throughout the season, or possible important soil deposition velocity changes throughout the season, as mentioned in the recent paper by Maseyk et al. (2014). This could be achieved with an optimization of the monthly flux of each component.

The analysis of the amplitude of the simulated seasonal cycle corresponds to the last two rows of Fig. 11 and also partly to the variance term of the MSE decomposition. The main features are

1. The improvement compared with the prior main results from the optimization of the OCS leaf uptake.

2. Smaller or negligible changes are observed at ALT and MLO stations when only the ocean fluxes are optimized (OPTIM_OCEAN_ONLY configuration), but significant improvements can be seen at southernmost stations (10\% variance error correction, not shown).

3. When only the soil uptake is optimized (OPTIM_SOIL_ONLY configuration), no improvement on the simulated amplitude is obtained.

4. The amplitude is too large in the prior for ORC at both ALT and MLO and remains too large at ALT after optimization, suggesting again that either LRU values or GPP fluxes are too large for high-latitude ecosystems. LPJ provides the best compromise in terms of amplitude when we consider all stations. However, the optimization of only one global coefficient for each flux does not allow for corrections of local flux biases, which leads to over- and underestimated amplitudes at different sites for both LPJ and ORC.

5. For CLM4CN, the simulated amplitude is too small at most stations, and cannot be corrected through the optimization of a global scaling factor because of the initial phase mismatch.
6. Finally, one should note that the amplitude of the atmospheric signal also depends on the transport model and potential vertical mixing errors. The version of the LMDZ model used here is believed to have too large mixing in the planetary boundary layer (PBL) (Patra et al., 2011; Locatelli et al., 2013), which would thus dampened the amplitude of the seasonal cycle.

\subsubsection{Annual mean atmospheric spatial gradients:}

We use the bias estimates from the MSE decomposition, which also accounts for any remaining trend mismatch, to analyze the annual mean gradients. As demonstrated by the results of the optimization of only one component (OPTIM_XXX_ONLY tests), all processes make a similar impact on the annual mean OCS concentrations. However, the optimization scheme leads to a degradation of the bias at MLO for the three models and the bias remains highly variable at other sites. The constraint imposed by the annual mean gradients cannot be significantly improved through optimization. The overall fit at some stations can be decreased (see for instance CLM4CN at MLO, Fig. 11) because of compensation by improvements at other sites. When testing the impact of the observation errors on the optimization, including a test with equal observation errors $(18 \mathrm{ppt})$, the results were not substantially modified.

\subsection{Joint constraint of atmospheric $\mathrm{OCS}$ and $\mathrm{CO}_{2}$ data to evaluate model GPP}

We now analyze and discuss potential constraints on the GPP of each ecosystem model that could be derived from the results of the OCS simulations (direct and inverse) and of additional $\mathrm{CO}_{2}$ simulations (see methods Sect. 2.5). The atmospheric $\mathrm{CO}_{2}$ concentrations simulated with the net $\mathrm{CO}_{2}$ ecosystem exchange (NEE = GPP-respiration) from the three DGVMs used for the OCS scenarios (including also standard fossil fuel emissions and ocean fluxes) are shown in the right-hand columns of Figs. 5 and 6. Figure 5 compares the smoothed temporal variations of the simulated $\mathrm{CO}_{2}$ and OCS concentrations at three stations (ALT, MLO and SPO). For $\mathrm{CO}_{2}$, all three models capture the observed seasonal cycle with nevertheless significant biases in terms of amplitude and/or phase, depending on the DGVM. As first described by Montzka et al. (2007), the OCS seasonal patterns are similar to $\mathrm{CO}_{2}$, but with noticeable differences in the timing of the maximum and minimum. The largest difference is observed at the SPO station with a phase shift of nearly 5 months between the two tracers. Additionally, Fig. 6 quantifies the contribution of the leaf uptake and of the GPP to the total simulated concentrations, for OCS and $\mathrm{CO}_{2}$, respectively. In the Northern Hemisphere, the phase and amplitude of the OCS seasonal cycle is primarily driven by the OCS leaf uptake, while for $\mathrm{CO}_{2}$ the seasonal cycle combines both GPP and respiration fluxes. Our OCS modeling framework thus provides support for a new constraint on GPP. Note, however, 

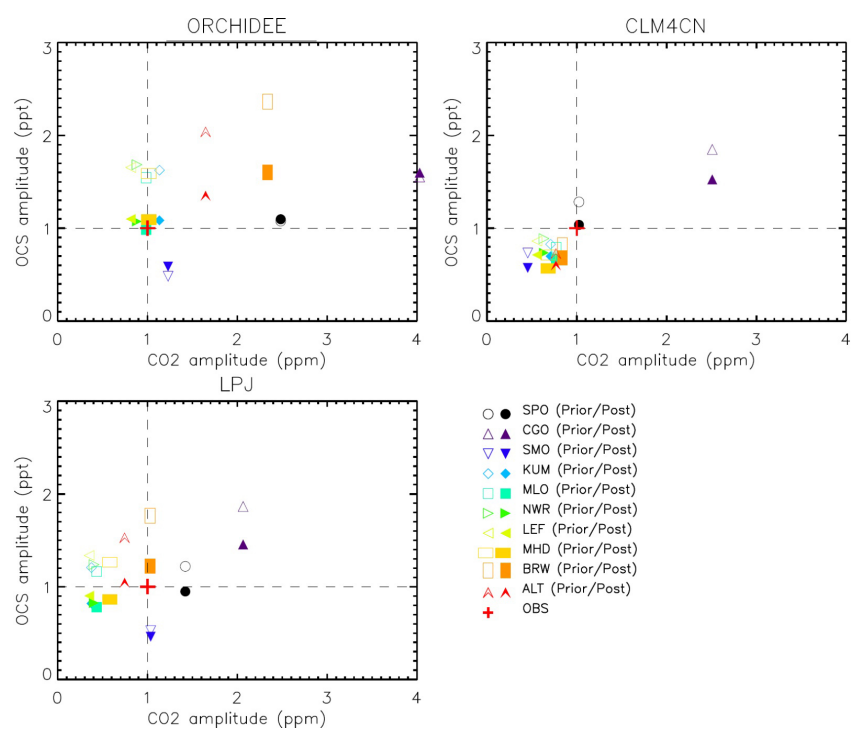

Figure 12. Scatter plots of normalized amplitudes of smoothed seasonal cycles of OCS versus those of $\mathrm{CO}_{2}$, before (open symbols) and after optimization (filled symbols) of OCS fluxes at 10 stations of the NOAA monitoring network, obtained from the STD_ORC, STD_CLM4CN and STD_LPJ setups for the forward simulations and the OPTIM_H-Er setup for the optimizations, over the period 2006-2010. Since the amplitude of the seasonal cycle in the observations at each site is used to normalize that of the simulations, the normalized amplitude of observations is 1 (red cross). Hence, a linear translation along the $y$ axis towards $Y=1$ characterizes the optimization process.

that for OCS, the other flux components (mainly the soil uptake and the ocean release) also contribute to the seasonal cycle but with nearly canceling effects.

We now discuss the implications of the simulated OCS and $\mathrm{CO}_{2}$ biases for each DGVM, separately. We refer to Fig. 12, which displays the normalized amplitude of the simulated OCS seasonal cycle as a function of the normalized amplitude of the simulated $\mathrm{CO}_{2}$ seasonal cycle at all stations (the normalization is done with respect to the observations).

\subsubsection{ORC model}

The analysis of the concentrations at boreal stations provides a first hint on northern high-latitude ecosystems. Both OCS and $\mathrm{CO}_{2}$ simulated seasonal amplitude are too large at ALT (by factors of 2 and 1.5, respectively). While the analysis based soley on $\mathrm{CO}_{2}$ would suggest either too large a GPP during boreal summer or too small an amplitude of the respiration seasonal cycle, the additional OCS diagnosis indicates that the GPP of ORC is indeed too large for high-latitude ecosystems. For OCS, uncertainties in LRU values also contribute to the model data mismatch. As suggested by Berkelhammer et al. (2013) the LRU values from Seibt et al. (2010) are on the upper range of the different estimates published so far $(+30 \%$ compared to the mean estimates). However, a
$45 \%$ reduction of the LRU that corresponds to the optimized fluxes of the INV_H-Er case (see Table 3) still produces an amplitude of the seasonal cycle at ALT larger than the observation by a factor 1.3 (Fig. 12). Such a remaining discrepancy thus confirms that ORC GPP is most likely overestimated at high latitudes. Note that for both tracers the phase of the seasonal cycle is relatively well captured (Fig. 5).

The signal at MLO integrates the contribution from the land (and ocean) fluxes of the whole Northern Hemisphere. In this case, there is relatively good agreement for the phase and amplitude of the $\mathrm{CO}_{2}$ seasonal cycle, while for OCS the amplitude is still too large (by a factor of 1.5). This suggests that the chosen LRU values are indeed too large and that too small GPP values at the mid- and low latitudes may compensate for the too large GPP values for boreal ecosystems, noted above. The result of the standard optimization leads to the right amplitude at MLO, which further indicates that the $50 \%$ global reduction of OCS leaf uptake is sufficient on average to compensate for too high a GPP at northern ecosystems and potentially too large an LRU.

The seasonal cycle at the remote SPO station is more difficult to interpret as (i) the amplitude of the cycle is 8 times smaller than at MLO for $\mathrm{CO}_{2}$ and (ii) all surfaces fluxes (i.e., from leaf, soil, and ocean) have a shared contribution to the overall seasonal cycle. The too large amplitude of ORC for $\mathrm{CO}_{2}$ reflects discrepancies in both GPP and respiration fluxes, but also in air-sea exchanges.

Overall, the joint OCS/CO 2 analysis points towards discrepancies in the ORC GPP, with overestimated values at high northern latitudes. Such conclusion directly corroborates the results obtained by Kuppel et al. (2014), using the same ecosystem model, when optimizing its parameters with eddy-covariance flux measurements $\left(\mathrm{CO}_{2}\right.$ and latent heat flux). They proposed a large reduction of the GPP for boreal broadleaf and boreal needleleaf forests.

\subsubsection{CLM4CN model}

The amplitude of the seasonal cycle simulated with CLM4CN is underestimated at nearly all stations for both OCS and $\mathrm{CO}_{2}$, with a modeled-to-observed ratio between 0.6 and 0.9, except at CGO where the amplitude is overestimated (Fig. 12). Moreover, as shown in Fig. 5, the phase shift in the OCS seasonal cycle at boreal stations (i.e., ALT) also occurs for $\mathrm{CO}_{2}$, with an earlier drawdown of the modeled concentrations compared to the observation (around 2 months). Such phase shift is much smaller or close to zero at temperate and low-latitude stations of the Northern Hemisphere.

The combined OCS and $\mathrm{CO}_{2}$ discrepancies point toward biases in the CLM4CN simulated gross carbon fluxes. First, the GPP of northern high-latitude ecosystems is most likely out of phase, with a too strong increase of photosynthesis in spring. Using only the $\mathrm{CO}_{2}$ tracer would suggest that one or both gross carbon fluxes are out of phase (photosynthesis and respiration). The benefit of the OCS tracer is to clearly point 
toward GPP as the major source of discrepancies, given that for OCS the leaf uptake, which is proportional to GPP, drives the overall seasonal cycle (see Fig. 6). Second, the amplitude of the GPP is also most likely underestimated for most ecosystems. While the $\mathrm{CO}_{2}$ concentrations do not allow one to find cause in GPP rather than respiration, the OCS points again towards too small a GPP during the peak of the growing season.

Increasing CLM4CN GPP by $20 \%$ and shifting its seasonal course by 2 months for high latitudes would create a significant improvement of both OCS and $\mathrm{CO}_{2}$ simulated concentrations. At SPO, the $\mathrm{CO}_{2}$ seasonal cycle is in good agreement with the observations, while the OCS seasonal cycle shows too large an amplitude and an earlier maximum similarly with the two other DGVMs.

\subsubsection{LPJ model}

Using the GPP from LPJ leads to intermediary results for the seasonal amplitude, for both tracers, with no systematic biases across stations (Fig. 12). If we consider boreal stations, the modeled seasonal amplitude for $\mathrm{CO}_{2}$ is $20 \%$ lower than the observations, while for OCS it is $50 \%$ higher. As noted above, the temporal variation of the OCS concentrations at these sites is slightly out of phase, with a too early drawdown in spring. This would suggest that the increase of boreal ecosystems GPP in spring is too early and too strong in LPJ (see for instance Fig. S4 in the Supplement). However, matching both OCS and $\mathrm{CO}_{2}$ atmospheric signals would also require a change in the temporal variation of the ecosystem respiration (to fit the $\mathrm{CO}_{2}$ signal).

At MLO, the phase shift becomes much lower for OCS. The too low amplitude for $\mathrm{CO}_{2}$ would suggest that either the GPP is underestimated during the peak of the growing season (it is much smaller than when using ORC, see Fig. S4) or that the respiration is too large during summertime. The OCS diagnostic with slightly too large amplitude at MLO (Fig. 5) suggests that (i) the main bias comes from the respiration, and (ii) the LRU values from Seibt et al. (2010) are likely overestimated (as already pointed out), which would explain the too large amplitude for OCS. As can be seen in Fig. S4, the LPJ model is the only one with respiration fluxes of the same magnitude as GPP fluxes, in temperate northern regions during mid- and late summer. Reducing the intensity of the respiration during this period would allow for larger annual variations of the $\mathrm{CO}_{2}$ concentrations, more consistent with the observations while still keeping the correct GPP-based representation of the OCS leaf uptake.

Overall, the above joint OCS and $\mathrm{CO}_{2}$ analysis points towards deficiencies for each model's gross carbon fluxes. The results obtained for the combined OCS-based and $\mathrm{CO}_{2}$-based analyses are coherent between the three models. For instance, the decrease of ORC GPP for temperate and high-latitude ecosystems or the phase shift of CLM4CN GPP would bring the different GPP estimates close together. However, some caution is still needed before drawing firm conclusions. For instance we should further investigate the following:

1. the spatial and temporal variations of the OCS-to- $\mathrm{CO}_{2}$ uptake ratio (LRU). More recent estimates based on additional in situ measurements are likely to provide lower LRU values than those of Seibt et al. (2010). LRU values have also been proven to vary depending on available light, and therefore to change according to seasons (Maseyk et al., 2014).

2. the seasonality of soil OCS uptake. Our modeling strategy, based on similarities between $\mathrm{H}_{2}$ and OCS uptake by soils, leads to a relatively small seasonal cycle of the OCS soil flux. Any large modifications of the seasonality of that component would directly impact our conclusions and to a certain extent our diagnostic on the gross carbon fluxes of the three DGVMs.

3. the impact of potential atmospheric transport errors. Indeed the mixing within the atmospheric transport model is still subject to significant uncertainties, which in turn may impact the conclusions that are directly linked to the amplitude of the seasonal cycle. Nonetheless, the LMDZ model has been used in many tracer transport studies with no strong known biases (Peylin et al., 2014).

\section{Conclusions}

Several studies have proposed a relationship between GPP and a concomitant OCS uptake by the vegetation, which would partly explain the atmospheric OCS concentration variations, yet the observed atmospheric measurements of OCS concentrations have never been used in a quantitative way to obtain information about the GPP of current global vegetation models. In this context, this study proposed a new set of global sources and sinks of OCS, using the GPP from three different global vegetation models to compute the leaf uptake of OCS. We further used the LMDZ atmospheric transport model to compute the temporal and spatial gradients of OCS concentration (as well as of $\mathrm{CO}_{2}$ ) in the atmosphere.

We proposed a global OCS budget fully based on parameterized processes that include large emissions by the ocean and important uptake by soil and vegetation. After the optimization of all flux components (within given ranges), we obtained a new flux scenario that (i) matches the observed OCS trend in the atmosphere (close to zero) and (ii) provides good agreement with the atmospheric concentrations (in terms of amplitude and phase of the seasonal cycle and annual mean gradients). Our modeling framework suggests that the GPP-related uptake of OCS mainly controls the seasonal cycle of atmospheric OCS concentrations, with much smaller influence from ocean and soil fluxes. 
More importantly, combining the information from OCS and $\mathrm{CO}_{2}$ atmospheric observations allowed us to highlight potential biases in the GPP of three dynamic global vegetation models. We showed that (i) for the ORC model, the terrestrial gross carbon fluxes in the Northern Hemisphere high latitudes are currently too large, (ii) for the CLM4CN model, the GPP is out of phase, with an uptake of carbon by northern high-latitude ecosystems that occurs too early in spring, and (iii) for the LPJ model, the respiration fluxes might be too large during the peak of the growing season on average in the Northern Hemisphere.

For the first time, our study quantifies the potential of OCS measurements to benchmark gross carbon fluxes from current DGVMs. It also highlights the need to better characterize the different processes that control the surface OCS fluxes and in particular the seasonality of soil uptake. From such a preliminary study, we foresee additional and complementary experiments that would

1. improve the inversion framework in order to optimize the temporal pattern of each flux component, using for instance a monthly time step optimization. This would provide further information on the potential biases associated to the seasonal variations of the GPP of each model.

2. combine the different models for the GPP-related uptake of OCS within a single inversion framework, where we would optimize a unique set of LRU coefficients (for each plant functional type (PFT)) together with the GPP fluxes of all DGVMs simultaneously.

3. optimize multi-data streams, based on both atmospheric OCS and $\mathrm{CO}_{2}$ data. This would allow for the separate optimization of GPP and respiration, using prior estimates from a given ecosystem model. Optimizing for both tracers would allow us to account for uncertainties associated with the different components of the $\mathrm{CO}_{2}$ and OCS budgets in the atmosphere simultaneously, relying on the GPP as a shared component. 


\section{Appendix A: Oceanic emissions of OCS}

\section{A1 Direct emissions}

The main production pathway of OCS is photochemical, hence light dependent and favored by UV-absorbing chromophoric dissolved organic matter (CDOM). The second pathway, the so-called "dark production", is temperature and organic-matter dependent. The two removal processes are hydrolysis ( $\mathrm{pH}$ dependent) and ventilation (dependent on temperature and wind speed). In the standard run defined by Launois et al. (2015), the direct emissions of OCS were equal to $813 \mathrm{Gg} \mathrm{Syr}^{-1}$, with $45 \%$ of emissions coming from the tropical ocean, but other scenarios (with different sets of parameters) yielded marine fluxes in the range of 573$1763 \mathrm{Gg} \mathrm{Syr}^{-1}$. To represent the high levels of uncertainty on the marine OCS emissions, an allowed range of variation of $70-150 \%$ of the standard run was used in the optimization runs (Table 2).

\section{A1.1 Indirect emissions}

As suggested by Barnes et al. (1997), OCS accounts for $0.7 \%$ of the oxidation products of DMS. Since DMS exhibits a short residence time (Koch et al., 1999; Chin et al., 2000; Kloster et al., 2006), here we assumed that $0.7 \%$ of the marine emissions of DMS were instantaneously converted into OCS. For that, we used a new version of the prognostic module developed by Belviso et al. (2012) to compute seawater DMS concentrations and DMS air-sea fluxes. This module, embedded within NEMO-PISCES similar to that of OCS, improves the representation of DMS dynamics in subtropical waters (Masotti et al., 2015).

$\mathrm{CS}_{2}$ emissions from oceans were not computed with NEMO-PISCES but taken from Kettle et al. (2002). We here assumed that $87 \%$ of the marine emissions of $\mathrm{CS}_{2}$ were instantaneously converted into OCS annually (Barnes et al., 1994).

\section{A2 Leaf uptake of OCS}

Atmospheric OCS follows the same path as $\mathrm{CO}_{2}$ to enter the leaves through stomata. However, since OCS is relatively heavier and larger than $\mathrm{CO}_{2}$, it diffuses less rapidly within the leaf (Berry et al., 2013, and references therein). As proven by laboratory and field studies, the leaf relative uptake of OCS compared to $\mathrm{CO}_{2}$ (LRU) is species-specific and highly variable, especially for $\mathrm{C} 4$ plants (maize, millet, etc.) for which the first product in carbon fixation during photosynthesis is realized on a four-carbon molecule) (Sandoval-Soto et al., 2005; Seibt et al., 2010). Nevertheless, major efforts have been made to estimate the relative deposition rates of OCS and $\mathrm{CO}_{2}$ (Sandoval-Soto et al., 2005, 2012; Campbell et al., 2008; Seibt et al., 2010; Stimler et al., 2010).

Here, we used the results of the study from Seibt et al. (2010), who estimated a global average value for $k_{\mathrm{LRU}}$ of
$2.8( \pm 10 \%)$. This estimate is, however, in the upper range of several estimates, since Sandoval-Soto et al. (2005), Stimler et al. (2012) and Berkelhammer et al. (2013) measured values between 1.45 and $3.03( \pm 20$ to $30 \%)$ for different species. In the Seibt et al. (2010) study, estimated LRU values for the different biomes were in the range of 1.55 (xerophytic woods and scrub) to 3.96 (cool/cold deciduous forests).

A map combining Köppen-Geiger climate zones with phenology-type from satellite land-cover data provided by the MODIS instrument was used to determine the major plant functional type for each region (Poulter et al., 2011; Kottek et al., 2006). Each species was assigned to a plant functional type (PFT) on the previously described map and then assigned the corresponding $k_{\mathrm{LRU}}$ relative uptake value from Seibt et al. (2010). The resulting global mask of $k_{\mathrm{LRU}}$ was then used to scale the GPP from the three DGVMs to obtain three different global seasonal OCS uptake fluxes by plants.

\section{A3 OCS uptake by oxic soils}

The approach relies on atmospheric observations that suggest that OCS uptake by oxic soils is proportional to $\mathrm{H}_{2}$ uptake by these soils. $\mathrm{H}_{2}$ uptake by soils, which represents about $80 \%$ of its total atmospheric loss, is believed to be driven by high- $\mathrm{H}_{2}$-affinity Streptomyces bacteria (Constant et al., 2010). OCS-degrading activity in heterotrophic soilbacteria was associated with isolates belonging to the genera Mycobacterium (Kato et al., 2008). Streptomyces and Mycobacterium are two important genera of the Actinobacteria taxon. Recent studies in genetics and cell biology of Streptomyces and Mycobacterium have revealed striking similarities in the developmental and morphological hallmarks of their lifecycles (Scherr and Nguyen, 2009). Moreover, optimal conditions for OCS (Van Diest and Kesselmeier, 2008) and $\mathrm{H}_{2}$ soil uptake (Smith-Downey et al., 2006), are rather similar: they both exhibit a broad temperature optimum between 20 and $30^{\circ} \mathrm{C}$ (for most soil types) and soil uptake is optimal for low soil moisture (15-25\% of saturation levels). Strong similarities between nighttime deposition velocities of OCS and $\mathrm{H}_{2}$, in terms of annual mean and ranges of variation, were also inferred from semi-continuous atmospheric observations in a semi-urban site located $20 \mathrm{~km} \mathrm{SW}$ of Paris, France. When plotted against $\mathrm{H}_{2}$ data, the OCS deposition velocities were roughly distributed around the $1: 1$ line (Belviso et al., 2013), but this relationship should perhaps not be applied at the global scale since the deposition velocities recorded in this semi-urban system were in the lower range of deposition velocities recorded by others. However, the airborne measurements carried out by $\mathrm{H}$. Chen above the United States provide support for the existence of such a relationship at the continental scale $(\mathrm{H}$. Chen, personal communication, 2014), but the slope of the relationship was only about 0.5 . Overall, we chose the value of 0.75 for our standard simulations. 


\section{Soil uptake of $\mathrm{H}_{2}: v_{\mathrm{H}_{2}}$ parameter in Eq. (3)}

Two different approaches for estimating $\nu_{\mathrm{H}_{2}}$ are used here. The first one is that from Morfopoulos et al. (2012), who implemented a hydrogen uptake module in the LPJ-WHyME model, including a description of atmospheric $\mathrm{H}_{2}$ diffusion through soil (Fick's first law) and of the biological processes of uptake which are limited by soil temperature and soil water content. The second approach is that from Bousquet et al. (2011) where an atmospheric inversion model of global and regional fluxes is used, based on a global network of flask observations of $\mathrm{H}_{2}$ concentration.

\section{A4 OCS emissions by anoxic soils}

OCS emissions by anoxic soils are largely based on the recent inventory by Whelan et al. (2013). Anoxic soil types were mapped accordingly to the representation used in the work by Wania et al. (2010) to represent seasonal methane emissions, as simulated using the LPJ-WHyME model. This way, anoxic soils activity were located via methane emissions and translated into hotspots of OCS emissions from anoxic soils, with similar temporal and spatial patterns. Each anoxic soil grid cell was associated the mean value for the anoxic soil OCS emission found in Whelan et al. (2013). However, because of the large uncertainties associated with the OCS flux inventories (see Fig. 3 in Whelan et al., 2013, "soil only" case), we finally assigned zero emission of OCS to rice paddies and $25 \mathrm{pmol} \mathrm{m}^{-2} \mathrm{~s}^{-1}$ to peatlands. Also note that unfortunately, salt marshes, which are strong emission sites of OCS (Whelan et al., 2013), are not taken into account in the LPJ-WHyME model.

\section{A5 DGVMs used and the TRENDY experiment}

We used the GPP simulated by three different models (ORCHIDEE, LPJ, CLM4CN) for a specific inter-comparison exercise, TRENDY, in order to derive the leaf uptake of OCS. We use monthly mean outputs from the so-called "S2" simulations, which indicates that the DGVMs were run with the same meteorological forcings (CRU-NCEP data set, see Ahlström et al., 2015) and changes in the atmospheric $\mathrm{CO}_{2}$ concentration, following the 20th century increases. Note that LPJ and ORCHIDEE models were provided originally at $0.5^{\circ} \times 0.5^{\circ}$ spatial resolution and CLM $4 \mathrm{CN}$ at $1.875^{\circ} \times 2.5^{\circ}$ spatial resolution. For our study we aggregated the fluxes at the transport model resolution $\left(3.7^{\circ} \times 2.5^{\circ}\right.$ spatial resolution).

The DGVM runs have been executed with a constant land use mask and disturbance turned off, which is supposed to represent the impact of climate and $\mathrm{CO}_{2}$ only on the system. The GPP and NEE monthly outputs from these TRENDY simulations have been taken for the 2000-2009 period. In the present paper, we focus on the phase and amplitude of the GPP seasonal cycle from each model. Note that we have used the NEE from each model to compute the atmospheric $\mathrm{CO}_{2}$ concentrations at the same stations as for OCS.

\section{A6 Optimization: setup and details about the cost function}

\section{A6.1 Optimization setup}

The optimization relies on the use of the LMDZ transport model that relates the surface fluxes to be optimized to the observed atmospheric concentrations. We used precalculated transport fields as in Peylin et al. (2005), where the outputs from the LMDZ transport model were only saved on a monthly time step. For each monthly mean observation, we selected the closest monthly mean simulated concentration to compare with. The optimized fluxes correspond to all sources and sinks of Table 2, to which the scaling coefficients are applied for each corresponding flux component.

For each parameter (scaling coefficient of a flux), we assigned a possible range of variation as well as a prior error ( $1 \sigma$ standard deviation). In the standard configuration, prior parameter values were equal to 1.00 and their prior uncertainty was set to 0.3 while the range of variation was set to $\pm 50 \%$, except for the direct oceanic emissions which has a range of variation from -30 to $+50 \%$ and an error kept to $30 \%$, and the OCS emitted through biomass burning and anthropogenic activities which has a range of variation of $\pm 10 \%$ and an error of $10 \%$.

These relatively large errors, combined with the range of variations defined for each flux component (Sect. 2.2), account for current uncertainties on the OCS processes that control the different sources and sinks. We also performed sensitivity tests for the optimization (see Table 3), using a limited $10 \%$ error and restricted ranges of variation for all scaling factors $( \pm 10 \%)$, referred as the low-error optimization scenario (OPTIM_L-Er). This theoretical test would assume that our OCS flux models (leaf and soil uptake, ocean release, etc.) are accurate which would in turn reveal the potential biases in the simulated atmospheric OCS levels (phase, amplitude, trend) due to other drivers of the OCS signal, such as GPP fluxes and transport model errors. The main objective is indeed to reveal any remaining biases (after the optimization), which could suggest corrections to the GPP fluxes, underlying the OCS leaf uptake model.

The different observations are assigned different weights in the optimization algorithm, represented as observation monthly errors. The choice of this so-called "observation error" is however difficult. It should gather the measurement error as well as the model error including the flux model error, the transport model error and the representation error (scale mismatch between the observed concentration at a given location and the model concentration at coarse scale). Usually the measurement error is relatively small compared to the modeling error. A proper assessment of model error could be done with the use of different models with different param- 
eterizations. However, for transport modeling studies this is usually not feasible and simpler approaches are used. As a first approximation, we used the RMSE of the prior modelobservation concentration differences at each station. We choose this simple approach and further averaged the RMSE by latitudinal bands to avoid the complexity of longitudinal differences in model skills. In this case, high-latitude stations such as ALT were displaying large prior MSE (nearly $2000 \mathrm{ppt}^{2}$ year ${ }^{-1}$, see Fig. 11) and were therefore assigned with a large observation error in the inversion. Note finally that we took slightly larger errors to account for the fact that the "observation error matrix" in the inversion is assumed to be diagonal and thus neglect all error correlations. However, we have done several sensitivity tests and in particular with equal observation errors between stations (set to $18 \mathrm{ppt}$ ), which did not lead to significantly different messages. Overall, the observation errors are set to a high value in Northern Hemisphere stations (26ppt), while stations from tropical regions are assigned $20 \mathrm{ppt}$ error and extratropical stations from the Southern Hemisphere are assigned 13 ppt error (these regions being mostly influenced by oceanic fluxes).

\section{A6.2 Cost function}

The first term of $J(\boldsymbol{x})$ represents the weighted data-model squared deviations, i.e., the misfit between the simulated outputs and the corresponding observational data. The second term represents the mismatch between optimized and prior values, weighted by the prior uncertainties on parameters. The $\mathbf{R}$ matrix corresponds to the observation error described above. Correlations in $\mathbf{R}$ are too difficult to assess and therefore neglected. Uncertainties on the a priori flux scalar values (B matrix) are set to large values (see below) which minimizes the influence of this term in the cost function. Moreover, error correlations between a priori parameter values were also neglected.

Given that we optimize scalars of the OCS surface fluxes and that the OCS destruction by $\mathrm{OH}$ in the atmosphere is fixed (i.e., prescribed and independent of the atmospheric OCS concentrations), the optimization problem is linear (i.e., the atmospheric concentrations linearly depend on the surface fluxes and their scaling factors). $\mathbf{M}(x)$ is thus equal to $\mathbf{M} x$, with $\mathbf{M}$ now representing the pre-calculated model concentration sensitivities to surface fluxes. With this assumption, the minimum of the cost function can be obtained directly with a matrix formulation of the inverse problem (see for instance Tarantola, 1987).

Note that in order to account for bounds on each flux parameter (to limit the optimal value in the prescribed range of variation), we iterated the scheme seven times. At each of the iterations, the optimized value for each parameter may be outside its range of variation. In this case, we fixed the parameter value (flux scalar) to its boundary and re-optimized excluding the parameter from the optimization. We then repeated the process until all parameters were fixed or within their range of variations. Note finally that assuming Gaussian errors allows us to estimate the posterior error covariance matrix on the parameter from a matrix formulation (see Tarantola, 1987) and thus to compute error correlations.

\section{A7 Simulated surface fluxes: regional and seasonal details of the obtained emissions and uptakes}

\section{A7.1 Direct oceanic emissions}

Photoproduction and hydrolysis are the main drivers of the mid- and high-latitude flux seasonality of both hemispheres: oceans take up OCS from the atmosphere in winter (Fig. 1, top), whereas summer fluxes are largely positive, between 3 and $10 \mathrm{pmol} \mathrm{m}^{2} \mathrm{~s}^{-1}$.

The tropical regions $\left(30^{\circ} \mathrm{S}-30^{\circ} \mathrm{N}\right)$ represent $45 \%$ of the yearly global OCS emissions and stay rather constant throughout the year (6 to $\left.8 \mathrm{pmol} \mathrm{m}^{2} \mathrm{~s}^{-1}\right)$. There, the major controlling factors are light and sea-surface temperature (SST) through SST-mediated dark production of OCS (Launois et al., 2014). Note the presence of an OCS emission hotspot off the coast of Somalia in July (up to $25 \mathrm{pmol} \mathrm{m}^{2} \mathrm{~s}^{-1}$ ), a feature linked to intense upwelling simulated by the NEMO-PISCES model on which our marine emission maps rely.

\section{A7.2 Indirect oceanic emissions}

Global maps of OCS emissions from DMS atmospheric oxidation for the months of January and July are provided in the Supplement (Fig. S1). Most of the OCS indirect emissions occur at high latitudes in the Southern Hemisphere, regions where the amplitude of the seasonal cycle is also the most important, with seasonal emissions varying between 4 and 7 Gg S per month (Fig. S1).

The OCS emissions based on the $\mathrm{CS}_{2}$ fluxes are mostly emitted in tropical regions, based on the $\mathrm{CS}_{2}$ flux maps by Kettle et al. (2002). These fluxes present a larger seasonal amplitude in the extratropical regions than in the tropics.

\section{A7.3 Oxic soil uptake of OCS}

The sensitivity of monthly soil OCS uptake rates to the different parametrizations $\left(\mathrm{H}_{2}\right.$ uptake and the ratio of OCS to $\mathrm{H}_{2}$ deposition velocity) is evaluated in Fig. S2, at the global scale and by large bands of latitude. The largest total uptake of OCS by oxic soils is obtained using the TEST_SOIL_MORF_1:1 scenario $\left(700 \mathrm{Gg} \mathrm{S} \mathrm{yr}^{-1}\right.$, with a ratio of OCS to $\mathrm{H}_{2}$ deposition velocity of unity). The smallest total uptake of OCS by oxic soils is obtained using the TEST_SOIL_BOUSQ_0.5:1 scenario $\left(330 \mathrm{Gg} \mathrm{S} \mathrm{yr}^{-1}\right)$.

Whatever the magnitude of the ratio between deposition velocities, the seasonal variations are more important in the extratropical areas of the Northern Hemisphere than elsewhere, and they differ between models of $\mathrm{H}_{2}$ deposition rates (TEST_SOIL_BOUSQ versus TEST_SOIL_MORF). In- 
deed, in TEST_SOIL_BOUSQ the OCS sink reaches a peak in spring whereas maximum uptake rates are seen in summer in TEST_SOIL_MORF. Using the TEST_SOIL_MORF_1:1 scenario, the extratropical areas of the Northern and Southern hemispheres each account for $30 \%$ of total uptake, and the remaining is taken up by tropical regions. Using the TEST_SOIL_BOUSQ_0.5:1 scenario, the extratropical areas of the Northern and Southern hemispheres, and the tropical regions account for $53 \%, 29 \%$ and $18 \%$ of the total uptake, respectively.

\section{A7.4 Soils net fluxes of OCS}

At the global scale, the monthly fluxes of OCS vary between 0 and $-28 \mathrm{Gg} \mathrm{S}$ per month (using Bousquet et al., 2011 for $\mathrm{H}_{2}$ flux) and between -15 and $-28 \mathrm{Gg} \mathrm{S}$ per month (using Morfopoulos et al., 2012 for $\mathrm{H}_{2}$ flux). These large soil flux seasonal variations will impact the simulated OCS atmospheric seasonal variations. We also notice that for all configurations, the largest amplitude of the OCS flux variations are found in the Northern Hemisphere.

Using the TEST_SOIL_BOUSQ_1:1 configuration, the simulated fluxes vary between +1 and $-15 \mathrm{Gg} S$ per month in the Northern Hemisphere (Fig. S2), while they range between +3 and $-8 \mathrm{GgS}$ per month using TEST_SOIL_ MORF_1:1. In the tropics, the simulated fluxes also display large variations (between -2 and $-8 \mathrm{GgS}$ with TEST_SOIL_MORF_1:1, between -11 and $-14 \mathrm{Gg}$ S per month with TEST_SOIL_BOUSQ_1:1). The same configurations lead to variations respectively between -3 and $-12 \mathrm{GgS}$ per month and between -7 and $-11 \mathrm{GgS}$ per month in the Southern Hemisphere.

\section{A7.5 Plant uptake of OCS}

Because OCS uptake by plants is represented in our models as a linear function of GPP (Eq. 2), the phase and amplitude of the seasonal variations in OCS plant uptake and GPP have the same patterns.

The ORC model displays stronger OCS uptake than the other models, throughout the year and especially during summer months (Fig. S3) due to its larger GPP. In ORC, the extratropical regions of the Northern Hemisphere are responsible for this summer uptake and account for about a third of the total plant uptake. The uptake of OCS in tropical regions is roughly constant and accounts for $45 \%$ of the total uptake. The remaining $20 \%$ is contributed by the extratropical regions of the Southern Hemisphere where the intensity of the summer maximum (about $35 \mathrm{Gg} \mathrm{S}$ month $^{-1}$ ) is roughly a quarter of that occurring in the Northern Hemisphere. Figure S3 reveals large differences in the amplitude of seasonal variations depending on which biospheric model is used to model the leaf uptake (the respective seasonal amplitudes are between 50 and $95 \mathrm{Gg} \mathrm{S}$ per month for ORC and CLM4CN). Large differences in the modeled OCS level seasonal phase can also be seen. Indeed, plant uptake reaches a peak in late spring in CLM4CN while maximum uptake occurs later in the year in the other models (the time lag is about 2 months). 


\section{The Supplement related to this article is available online at doi:10.5194/acp-15-9285-2015-supplement.}

Acknowledgements. Special thanks are due to the National Oceanic and Atmospheric Administration (NOAA) Global Monitoring Division (GMD) in Boulder, $\mathrm{CO}$, for providing the observational data used in this study. We are equally grateful to Elliott Campbell for sharing the flux estimates from Kettle et al. (2002) and to Samuel Levis for letting us use their global dynamic vegetation model NCAR-CLM4 to compare with the two other models. The salary of Thomas Launois was partly supported by the European Research Council project SOLCA (grant agreement no. 338264).

Edited by: S. Kloster

\section{References}

Ahlström, A., Raupach, M. R., Schurgers, G., Smith, B., Arneth, A., Jung, M., and Zeng, N.: The dominant role of semi-arid ecosystems in the trend and variability of the land $\mathrm{CO}_{2}$ sink, Science, 348, 895-899, 2015.

Barnes, I., Becker, K. H., and Patroescu, I.: The tropospheric oxidation of dimethyl sulfide: A new source of carbonyl sulfide, Geophys. Res. Lett., 21, 2389-2392, 1997.

Beer, C., Reichstein, M., Tomelleri, E., Ciais, P., Jung, M., Carvalhais, N., and Papale, D.: Terrestrial gross carbon dioxide uptake: global distribution and covariation with climate, Science, 329, 8340-838, 2010.

Belviso, S., Nguyen, B. C., and Allard, P.: Estimate of carbonyl sulfide (OCS) volcanic source strength deduced from $\mathrm{OCS} / \mathrm{CO}_{2}$ ratios in volcanic gases. Geophys. Res. Lett., 13, 133-136, 1986.

Belviso, S., Masotti, I., Tagliabue, A., Bopp, L., Brockmann, P., Fichot, C., and Fukuchi, M.: DMS dynamics in the most oligotrophic subtropical zones of the global ocean, Biogeochemistry, 110, 215-241, 2012.

Belviso, S., Schmidt, M., Yver, C., Ramonet, M., Gros, V., and Launois, T.: Strong similarities between nighttime deposition velocities of carbonyl sulphide and molecular hydrogen inferred from semi-continuous atmospheric observations in Gif-sur-Yvette, Paris region, Tellus B, 65, 20719, doi:10.3402/tellusb.v65i0.20719, 2013.

Berkelhammer, M., Asaf, D., Still, C., Montzka, S., Noone, D., Gupta, M., and Yakir, D.: Constraining surface carbon fluxes using in situ measurements of carbonyl sulfide and carbon dioxide, Global Biogeochem. Cy., 28, 161-179, 2014.

Berry, J., Wolf, A., Campbell, J. E., Baker, I., Blake, N., Blake, D., and Zhu, Z.: A coupled model of the global cycles of carbonyl sulfide and CO2: A possible new window on the carbon cycle, J. Geophys. Res.-Biogeo, 118, 842-852, 2013.

Bousquet, P., Ringeval, B., Pison, I., Dlugokencky, E. J., Brunke, E.G., Carouge, C., Chevallier, F., Fortems-Cheiney, A., Frankenberg, C., Hauglustaine, D. A., Krummel, P. B., Langenfelds, R. L., Ramonet, M., Schmidt, M., Steele, L. P., Szopa, S., Yver, C., Viovy, N., and Ciais, P.: Source attribution of the changes in atmospheric methane for 2006-2008, Atmos. Chem. Phys., 11, 3689-3700, doi:10.5194/acp-11-3689-2011, 2011.
Campbell, J. E., Carmichael, G. R., Chai, T., Mena-Carrasco, M., Tang, Y., Blake, D. R., and Stanier, C. O.: Photosynthetic control of atmospheric carbonyl sulfide during the growing season, Science, 322, 1085-1088, 2008.

Carouge, C., Bousquet, P., Peylin, P., Rayner, P. J., and Ciais, P.: What can we learn from European continuous atmospheric $\mathrm{CO}_{2}$ measurements to quantify regional fluxes - Part 1: Potential of the 2001 network, Atmos. Chem. Phys., 10, 3107-3117, doi:10.5194/acp-10-3107-2010, 2010a.

Carouge, C., Rayner, P. J., Peylin, P., Bousquet, P., Chevallier, F., and Ciais, P.: What can we learn from European continuous atmospheric $\mathrm{CO}_{2}$ measurements to quantify regional fluxes - Part 2: Sensitivity of flux accuracy to inverse setup, Atmos. Chem. Phys., 10, 3119-3129, doi:10.5194/acp-10-3119-2010, 2010 b.

Chevallier, F., Feng, L., Bösch, H., Palmer, P. I., and Rayner, P. J.: On the impact of transport model errors for the estimation of $\mathrm{CO}_{2}$ surface fluxes from GOSAT observations, Geophys. Res. Lett., 37, L21803, doi:10.1029/2010GL044652, 2010.

Chin, M. and Davis, D. D.: Global sources and sinks of OCS and CS2 and their distributions, Global Biogeochem. Cy., 7, 321337, 1993a.

Chin, M. and Davis, D. D.: A reanalysis of carbonyl sulfide as a source of stratospheric background sulfur aerosol. J. Geophys. Res.-Atmos., 100, 8993-9005, 1993b.

Chin, M., Rood, R. B., Lin, S. J., Müller, J. F., and Thompson, A. M.: Atmospheric sulfur cycle simulated in the global model GOCART: Model description and global properties, J. Geophys. Res.-Atmos., 105, 24671-24687, 2000.

Ciais, P., Reichstein, M., Viovy, N., Granier, A., Ogée, J., Allard, V., and Valentini, R.: Europe-wide reduction in primary productivity caused by the heat and drought in 2003, Nature, 437, 529-533, 2005.

Constant, P., Chowdhury, S. P., Pratscher, J., and Conrad, R.: Streptomycetes contributing to atmospheric molecular hydrogen soil uptake are widespread and encode a putative high-affinity [NiFe]-hydrogenase, Environ. Microbiol., 12, 821-829, 2010.

Conway, T. J., Tans, P. P., Waterman, L. S., Thoning, K. W., Kitzis, D. R., Masarie, K. A., and Zhang, N.: Evidence for interannual variability of the carbon cycle from the National Oceanic and Atmospheric Administration/Climate Monitoring and Diagnostics Laboratory global air sampling network. J. Geophys. Res.Atmos., 99, 22831-22855, 1994.

Geng, C. and $\mathrm{Mu}$, Y.: Carbonyl sulfide and dimethyl sulfide exchange between trees and the atmosphere, Atmos. Environ., 40, 1373-1383, 2006.

Grace, J. and Rayment, M.: Respiration in the balance, Nature, 404, 819-820, 2000.

Hauglustaine, D. A., Brasseur, G. P., Walters, S., Rasch, P. J., Müller, J. F., Emmons, L. K., and Carroll, M. A.: MOZART, a global chemical transport model for ozone and related chemical tracers: 2. Model results and evaluation, J. Geophys. Res.Atmos., 103, 28291-28335, 1998.

Hourdin, F., Musat, I., Bony, S., Braconnot, P., Codron, F., Dufresne, J. L., and Lott, F.: The LMDZ4 general circulation model: climate performance and sensitivity to parametrized physics with emphasis on tropical convection, Clim. Dynam., 27, 787-813, 2006. 
Kato, H., Saito, M., Nagahata, Y., and Katayama, Y.: Degradation of ambient carbonyl sulfide by Mycobacterium spp. in soil, Microbiology, 154, 249-255, 2008.

Kesselmeier, J., Teusch, N., and Kuhn, U.: Controlling variables for the uptake of atmospheric carbonyl sulfide by soil. J. Geophys. Res.-Atmos., 104, 11577-11584, 1999.

Kettle, A. J., Kuhn, U., Von Hobe, M., Kesselmeier, J., and Andreae, M. O.: Global budget of atmospheric carbonyl sulfide: Temporal and spatial variations of the dominant sources and sinks, J. Geophys. Res.-Atmos., 107, doi:10.1029/2002JD002187, 2002.

Kloster, S., Feichter, J., Maier-Reimer, E., Six, K. D., Stier, P., and Wetzel, P.: DMS cycle in the marine ocean-atmosphere system a global model study, Biogeosciences, 3, 29-51, doi:10.5194/bg3-29-2006, 2006.

Knohl, A., Werner, R. A., Brand, W. A., Buchmann, N.: Shortterm variations in $\delta 13 \mathrm{C}$ of ecosystem respiration reveals link between assimilation and respiration in a deciduous forest, Oeocologia, 142, 70-82, 2005.

Kobayashi, K. and Salam, M. U.: Comparing simulated and measured values using mean squared deviation and its components, Agron. J., 92, 345-352, 2000.

Koch, D., Jacob, D., Tegen, I., Rind, D., and Chin, M.: Tropospheric sulfur simulation and sulfate direct radiative forcing in the Goddard Institute for Space Studies general circulation model. J. Geophys. Res.-Atmos., 104, 23799-23822, 1999.

Kottek, M., Grieser, J., Beck, C., Rudolf, B., and Rubel, F.: World map of the Köppen-Geiger climate classification updated. Meteorol. Z., 15, 259-263, 2006.

Krinner, G., Viovy, N., de Noblet-Ducoudré, N., Ogée, J., Polcher, J., Friedlingstein, P., and Prentice, I. C.: A dynamic global vegetation model for studies of the coupled atmospherebiosphere system, Global Biogeochem. Cy., 19, GB1015, doi:10.1029/2003GB002199, 2005.

Kuppel, S., Peylin, P., Maignan, F., Chevallier, F., Kiely, G., Montagnani, L., and Cescatti, A.: Model-data fusion across ecosystems: from multisite optimizations to global simulations, Geosci. Model Dev., 7, 2581-2597, doi:10.5194/gmd-7-25812014, 2014.

Lasslop, G., Reichstein, M., Papale, D., Richardson, A. D., Arneth, A., Barr, A., and Wohlfahrt, G.: Separation of net ecosystem exchange into assimilation and respiration using a light response curve approach: critical issues and global evaluation. Glob. Change Biol., 16, 187-208, 2010.

Launois, T., Belviso, S., Bopp, L., Fichot, C. G., and Peylin, P.: A new model for the global biogeochemical cycle of carbonyl sulfide - Part 1: Assessment of direct marine emissions with an oceanic general circulation and biogeochemistry model, Atmos. Chem. Phys., 15, 2295-2312, doi:10.5194/acp-15-22952015, 2015.

Locatelli, R., Bousquet, P., Chevallier, F., Fortems-Cheney, A., Szopa, S., Saunois, M., Agusti-Panareda, A., Bergmann, D., Bian, H., Cameron-Smith, P., Chipperfield, M. P., Gloor, E., Houweling, S., Kawa, S. R., Krol, M., Patra, P. K., Prinn, R. G., Rigby, M., Saito, R., and Wilson, C.: Impact of transport model errors on the global and regional methane emissions estimated by inverse modelling, Atmos. Chem. Phys., 13, 99179937, doi:10.5194/acp-13-9917-2013, 2013.
Lorimer, G. H. and Pierce, J.: Carbonyl sulfide: an alternate substrate for but not an activator of ribulose-1, 5-bisphosphate carboxylase, J. Biol. Chem., 264, 2764-2772, 1989.

Marland, G., Brenkert, A., and Olivier, J.: $\mathrm{CO}_{2}$ from fossil fuel burning: a comparison of ORNL and EDGAR estimates of national emissions, Environ. Sci. Policy, 2, 265-273, 1999.

Maseyk, K., Berry, J. A., Billesbach, D., Campbell, J. E., Torn, M. S., Zahniser, M., and Seibt, U.: Sources and sinks of carbonyl sulfide in an agricultural field in the Southern Great Plains, P. Natl. Acad. Sci. USA, 111, 9064-9069, 2014.

Masotti, I., Belviso, S., Bopp, L., Tagliabue, A., and Bucciarelli, E.: Effects of light and phosphorus on summer DMS dynamics in subtropical waters using a global ocean biogeochemical model. Environ. Chem., in press, 2015.

Montzka, S. and Tans, P.: Can Carbonyl Sulfide Help Constrain Gross Vegetative Fluxes of Carbon Dioxide?, AGU Fall Meeting Abstracts, Vol. 1, p. 4, 2004.

Montzka, S. A., Calvert, P., Hall, B. D., Elkins, J. W., Conway, T. J., Tans, P. P., and Sweeney, C.: On the global distribution, seasonality, and budget of atmospheric carbonyl sulfide (COS) and some similarities to $\mathrm{CO}_{2}$, J. Geophys. Res.-Atmos., 112, D09302, doi:10.1029/2006JD007665, 2007.

Morfopoulos, C., Foster, P. N., Friedlingstein, P., Bousquet, P., and Prentice, I. C.: A global model for the uptake of atmospheric hydrogen by soils, Global Biogeochem. Cy., 26, GB3013, doi:10.1029/2011GB004248, 2012.

Nguyen, B. C., Mihalopoulos, N., Putaud, J. P., and Bonsang, B.: Carbonyl sulfide emissions from biomass burning in the tropics, J. Atmos. Chem., 22, 55-65, 1995.

Ogawa, T., Noguchi, K., Saito, M., Nagahata, Y., Kato, H., Ohtaki, A., Nakayama, H., Dohmae, N., Matsushita, Y., Odaka, M., Yohda, M., Nyunoya, H., and Katayama, Y.: Carbonyl Sulfide hydrolase from Thiobacillus thioparus Strain THI115 is one of the $\beta$ Carbonic Anhydrase family enzymes, J. Am. Chem. Soc., 135, 3818-3825, doi:10.1021/ja307735e, 2013.

Patra, P. K., Houweling, S., Krol, M., Bousquet, P., Belikov, D., Bergmann, D., Bian, H., Cameron-Smith, P., Chipperfield, M. P., Corbin, K., Fortems-Cheiney, A., Fraser, A., Gloor, E., Hess, P., Ito, A., Kawa, S. R., Law, R. M., Loh, Z., Maksyutov, S., Meng, L., Palmer, P. I., Prinn, R. G., Rigby, M., Saito, R., and Wilson, C.: TransCom model simulations of $\mathrm{CH}_{4}$ and related species: linking transport, surface flux and chemical loss with $\mathrm{CH}_{4}$ variability in the troposphere and lower stratosphere, Atmos. Chem. Phys., 11, 12813-12837, doi:10.5194/acp-11-12813-2011, 2011.

Peylin, P., Rayner, P. J., Bousquet, P., Carouge, C., Hourdin, F., Heinrich, P., Ciais, P., and AEROCARB contributors: Daily $\mathrm{CO}_{2}$ flux estimates over Europe from continuous atmospheric measurements: 1, inverse methodology, Atmos. Chem. Phys., 5, 3173-3186, doi:10.5194/acp-5-3173-2005, 2005.

Peylin, P., Bacour, C., MacBean, N., Leonard, S., Maignan, F., Thum, T., and Santaren, D. L.: How best to optimize a global process-based carbon land surface model?, Geophys. Res. Abstr., 16, p. 10302, EGU General Assembly 2014, Vienna, Austria, 2014.

Piovesan, G. and Adams, J. M.: Carbon balance gradient in European forests: interpreting EUROFLUX, J. Veg. Sci., 11, 923926, 2000.

Poulter, B., Ciais, P., Hodson, E., Lischke, H., Maignan, F., Plummer, S., and Zimmermann, N. E.: Plant functional type map- 
ping for earth system models, Geosci. Model Dev., 4, 993-1010, doi:10.5194/gmd-4-993-2011, 2011.

Poulter, B., Frank, D., Ciais, P., Myneni, R. B., Andela, N., Bi, J., and Van der Werf, G. R.: Contribution of semi-arid ecosystems to interannual variability of the global carbon cycle, Nature, 509, 600-603, 2014.

Protoschill-Krebs, G. and Kesselmeier, J.: Enzymatic Pathways for the Consumption of Carbonyl Sulphide (COS) by Higher Plants, Bot. Acta, 105, 206-212, 1992.

Protoschill-Krebs, G., Wilhelm, C., and Kesselmeier, J.: Consumption of carbonyl sulphide by Chlamydomonas reinhardtii with different activities of carbonic anhydrase (CA) induced by different $\mathrm{CO}_{2}$ growing regimes, Bot. Acta, 108, 445-448, 1995.

Protoschill-Krebs, G., Wilhelm, C., and Kesselmeier, J.: Consumption of carbonyl sulphide (COS) by higher plant carbonic anhydrase (CA), Atmos. Environ., 30, 3151-3156, 1996.

Reichstein, M., Falge, E., Baldocchi, D., Papale, D., Aubinet, M., Berbigier, P., and Valentini, R.: On the separation of net ecosystem exchange into assimilation and ecosystem respiration: review and improved algorithm, Glob. Change Biol., 11, 14241439. 2005

Sandoval-Soto, L., Stanimirov, M., von Hobe, M., Schmitt, V., Valdes, J., Wild, A., and Kesselmeier, J.: Global uptake of carbonyl sulfide (COS) by terrestrial vegetation: Estimates corrected by deposition velocities normalized to the uptake of carbon dioxide $\left(\mathrm{CO}_{2}\right)$, Biogeosciences, 2, 125-132, doi:10.5194/bg-2-1252005, 2005.

Sandoval-Soto, L., Kesselmeier, M., Schmitt, V., Wild, A., and Kesselmeier, J.: Observations of the uptake of carbonyl sulfide (COS) by trees under elevated atmospheric carbon dioxide concentrations, Biogeosciences, 9, 2935-2945, doi:10.5194/bg-92935-2012, 2012.

Scartazza, A., Mata, C., Matteucci, G., Yakir, D., Moscatello, S., and Brugnoli, E.: Comparisons of $\delta 13 \mathrm{C}$ of photosynthetic products and ecosystem respiratory $\mathrm{CO}_{2}$ and their responses to seasonal climate variability, Oeocologia, 140, 340-351, 2004.

Schaphoff, S., Lucht, W., Gerten, D., Sitch, S., Cramer, W., and Prentice, I. C.: Terrestrial biosphere carbon storage under alternative climate projections, Climatic Change, 74, 97-122, 2006.

Schenk, S., Kesselmeier, J., and Anders, E.: How does the exchange of one oxygen atom with sulfur affect the catalytic cycle of carbonic anhydrase?, Chem-Eur. J., 10, 3091-3105, 2004.

Scherr, N. and Nguyen, L.: Mycobacterium versus Streptomyces we are different, we are the same, Curr. Opin. Microbiol., 12, 699-707, 2009.

Seibt, U., Wingate, L., Lloyd, J., and Berry, J. A.: Diurnally variable $\delta 180$ signatures of soil $\mathrm{CO}_{2}$ fluxes indicate carbonic anhydrase activity in a forest soil, J. Geophys. Res.-Biogeo., 111, G04005, doi:10.1029/2006JG000177, 2006.

Seibt, U., Kesselmeier, J., Sandoval-Soto, L., Kuhn, U., and Berry, J. A.: A kinetic analysis of leaf uptake of COS and its relation to transpiration, photosynthesis and carbon isotope fractionation, Biogeosciences, 7, 333-341, doi:10.5194/bg-7-333-2010, 2010.

Simmons, J. S., Klemedtsson, L., Hultberg, H., and Hines, M. E.: Consumption of atmospheric carbonyl sulfide by coniferous boreal forest soils. J. Geophys. Res.-Atmos., 104, 11569-11576, 1999.

Sitch, S., Smith, B., Prentice, I. C., Arneth, A., Bondeau, A., Cramer, W., and Venevsky, S.: Evaluation of ecosystem dynam- ics, plant geography and terrestrial carbon cycling in the LPJ dynamic global vegetation model, Glob. Change Biol., 9, 161-185, 2003.

Sitch, S., Friedlingstein, P., Gruber, N., Jones, S. D., MurrayTortarolo, G., Ahlström, A., Doney, S. C., Graven, H., Heinze, C., Huntingford, C., Levis, S., Levy, P. E., Lomas, M., Poulter, B., Viovy, N., Zaehle, S., Zeng, N., Arneth, A., Bonan, G., Bopp, L., Canadell, J. G., Chevallier, F., Ciais, P., Ellis, R., Gloor, M., Peylin, P., Piao, S. L., Le Quéré, C., Smith, B., Zhu, Z., and Myneni, R.: Recent trends and drivers of regional sources and sinks of carbon dioxide, Biogeosciences, 12, 653679, doi:10.5194/bg-12-653-2015, 2015.

Smith-Downey, N. V., Randerson, J. T., and Eiler, J. M.: Temperature and moisture dependence of soil $\mathrm{H} 2$ uptake measured in the laboratory. Geophys. Res. Lett., 33, L14813, doi:10.1029/2006GL026749, 2006.

Stimler, K., Montzka, S. A., Berry, J. A., Rudich, Y., and Yakir, D.: Relationships between carbonyl sulfide (COS) and CO2 during leaf gas exchange, New Phytol., 186, 869-878, 2010.

Suntharalingam P., Kettle A. J., Montzka S. M., and Jacob D. J.: Global 3-D model analysis of the seasonal cycle of atmospheric carbonyl sulfide: Implications for terrestrial vegetation uptake, Geophys. Res. Lett., 35, L19801, doi:10.1029/2008GL034332, 2008.

Takahashi, T., Sutherland, S. C., Wanninkhof, R., Sweeney, C., Feely, R. A., Chipman, D. W., and De Baar, H. J.: Climatological mean and decadal change in surface ocean $\mathrm{pCO}_{2}$, and net seaair $\mathrm{CO}_{2}$ flux over the global oceans, Deep Sea Res. Pt. II, 56, 554-577, 2009.

Tarantola, A.: Inverse problems theory, Methods for Data Fitting and Model Parameter Estimation, Elsevier, Southampton, 1987.

Thornton, P. E., Lamarque, J.-F., Rosenbloom, N. A., and Mahowald, N. M.: Influence of carbon-nitrogen cycle coupling on land model response to $\mathrm{CO}_{2}$ fertilization and cliate variability, Global Biogeochem. Cy., 21, 1-15, 2007.

van der Werf, G. R., Randerson, J. T., Giglio, L., Collatz, G. J., Mu, M., Kasibhatla, P. S., Morton, D. C., DeFries, R. S., Jin, Y., and van Leeuwen, T. T.: Global fire emissions and the contribution of deforestation, savanna, forest, agricultural, and peat fires (19972009), Atmos. Chem. Phys., 10, 11707-11735, doi:10.5194/acp10-11707-2010, 2010.

Van Diest, H. and Kesselmeier, J.: Soil atmosphere exchange of carbonyl sulfide (COS) regulated by diffusivity depending on waterfilled pore space, Biogeosciences, 5, 475-483, doi:10.5194/bg-5475-2008, 2008.

Wania, R., Ross, I., and Prentice, I. C.: Implementation and evaluation of a new methane model within a dynamic global vegetation model: LPJ-WHyMe v1.3.1, Geosci. Model Dev., 3, 565-584, doi:10.5194/gmd-3-565-2010, 2010.

Whelan, M. E., Min, D. H., and Rhew, R. C.: Salt marsh vegetation as a carbonyl sulfide (COS) source to the atmosphere, Atmos. Environ., 73, 131-137, 2013.

White, M. L., Zhou, Y., Russo, R. S., Mao, H., Talbot, R., Varner, R. K., and Sive, B. C.: Carbonyl sulfide exchange in a temperate loblolly pine forest grown under ambient and elevated $\mathrm{CO}_{2}$, Atmos. Chem. Phys., 10, 547-561, doi:10.5194/acp-10-547-2010, 2010.

Wingate, L., Seibt, U., Maseyk, K., OgEE, J., Almeida, P., Yakir, D., and Mencuccini, M., Evaporation and carbonic anhydrase activ- 
ity recorded in oxygen isotope signatures of net $\mathrm{CO}_{2}$ fluxes from a Mediterranean soil, Glob. Change Biol., 14, 2178-2193, 2008.

Wingate, L., Ogée, J., Burlett, R., Bosc, A., Devaux, M., Grace, J., and Gessler, A.: Photosynthetic carbon isotope discrimination and its relationship to the carbon isotope signals of stem, soil and ecosystem respiration, New Phytol., 188, 576-589, 2010.

Wöhlfahrt, G., Brilli, F., Hörtnagl, L., Xu, X., Bingemer, H., Hansel, A., and Loreto, F.: Carbonyl sulfide (COS) as a tracer for canopy photosynthesis, transpiration and stomatal conductance: potential and limitations, Plant. Cell Environ., 35, 657-667, 2012.
Xu, X., Bingemer, H. G., Georgii, H. W., Schmidt, U., and Bartell, U.: Measurements of carbonyl sulfide (COS) in surface seawater and marine air, and estimates of the air-sea flux from observations during two Atlantic cruises, J. Geophys. Res.-Atmos., 106, 3491-3502, 2001 